\title{
4. THE KUWAIT OIL COMPANY, (COLOR) PHOTOGRAPHY, AND IRIDESCENT IMPRESSIONS
}

In the mid-twentieth century, Kuwaiti oil flowed in abundance, and the town of Kuwait experienced an unprecedented urban transformation that led to the creation of modern Kuwait City. Moreover, the transformation of urban space gained great visual momentum, and not just in the form of fossil-fuel fueled views from above. The Kuwait Oil Company (KOC) also favored urban images of Kuwait and presented the capital city as a symbol of the prosperity and progress that oil, and hence the oil company, was supposedly bringing to the country. To this end the KOC stimulated the text- and image-based metaphor of "making the desert bloom," which color photography was best able to communicate.

Initially, Kuwait City held no relevance for the oil company, for the firm's headquarters and operations were located in Ahmadi (the oil company town), the oil harbor (Minā' $a l-A h m \bar{a} d \bar{\imath})$, and the oil fields more than forty kilometers south of the capital. KOC's photographic scope, however, exceeded the choreography of oil fields, oil rigs, pipelines, storage tanks, refineries, oil harbors, oil workers, and Ahmadi. Other urban spaces and people of the country that the KOC was operating in were gradually incorporated into the KOC's visual cosmos, even if they were not directly related to the company's primary activities. In fact, a substantial share of the professional color photography commissioned by the oil company in the 1950s depicted Kuwait City exclusively.

One might imagine that the company was kept busy enough controlling the fastflowing multimillion-dollar streams of petroleum but, in view of growing anti-imperialist and Arab-nationalist sentiments at the time, the curation of its public image became a pivotal concern. By visually claiming Kuwait's capital as part of its sphere of influence, the Anglo-American company attempted to stimulate acceptance of its own operations in the country by presenting the progress this coastal city-state was experiencing in positive terms, as this chapter will show.

To this end, the firm engaged professional photographers to shoot Kuwait City in expensive large-format color images. While these were not the first color images ever taken of Kuwait, the quality, format, size, and especially quantity of the new photographs was unprecedented: it was the first time that Kuwait City had appeared in such beaming colors in not one or a hand-full of shots, but in several albums of large-scale photographs. These images not only established Kuwait City as a beautified motif from which anything that could have challenged its positive progressive appearance was hidden from view. 
They also relied heavily on the use of color. Color photography was crucial in conveying how the coastal village was apparently "awakening" to life once it started partaking in the consumerist lifestyle petro-modernity projected and the oil company encouraged. The photos, which wove a colorful picture of a modernizing Arab City, had one basic message: petroleum has switched on the lights. Fossil-fueled visualization technologies had made Kuwait viewable from above and, for passengers flying in at night, the expanding electrification had created breathtaking pictures of Kuwait City against the backdrop of the dark desert, a sight that many described with fascination. The KOC's framing of Kuwait City not only with light but with photographic colors represents another pivotal case in point of the visually seductive aesthetic effect of petro-modernity's iridescence.

The KOC created illustrated publications such as The Story of Kuwait and commissioned professional photographers to positively convey its operations in the country and the effect petroleum was having on Kuwait. Ever since the first issue, The Story of Kuwait metaphorized the promise of petroleum as "making the desert (meaning Kuwait) bloom." In subsequent issues, (black-and-white) photography was crucial in presenting Kuwait City's brand-new architecture as a concrete garden rising from the desert. When critique of the oil company climaxed around 1956-57, the company stepped up its game and commissioned a series of professional color photographs through which the idea of "making the desert bloom" could be depicted as "switching on the colorful lights." Now, Kuwait City emerged as an iridescent flower against the endless sand-colored background of the desert and the pre-oil town. The company no longer needed to say "This is what petroleum can do; we made this happen" because the color images spoke for themselves. As the corporate color photos of Kuwait subsequently proliferated in public displays and exhibitions outside the country, they were received as authentic representations of the citystate. Yet a closer inspection and a comparison with other photographic documentations, such as by Kuwaiti photographer Tareq Sayid Rajab, reveals that the corporate shots were highly selective in regard to which parts of Kuwait City's transformation were show and which parts were hidden from view.

\subsection{Oil Company Photography}

Oil companies operating across the world have gained tremendous influence by producing data and information on their concessional territories that go far beyond the actual scene of oil production. They have also made use of a wide range of often novel media not only for surveying and prospecting but also for product and corporate image promotion as well as to shape public opinion. For example, oil companies including the KOC have invested substantially in documentary film production in Iran, Iraq, and Kuwait in order to create a broad public acceptance of their operations as Mona Damluji has shown. ${ }^{1}$

${ }^{1}$ See Damluji, "Petroleum's Promise." 
The case of the KOC indicates that photography, especially color photography, was another pivotal medium which, from the mid-1950s onward, the company started to use deliberately to improve its public relations. By the 1960s, many oil companies operating in the Gulf region and the Arabian Peninsula had already become substantial producers of photography and today, "they own the oldest collections in most of the oil producing countries visited. Their collections cover most aspects of local social life, and also include landscapes and city construction documentation." 2 They set up photographic archives, established in-house photographic units with staff photographers, or commissioned well-known professional photographers to take photographs on their behalf. They then utilized these pictures in their company publications and displays. They also offered their photographic collections to such other interested parties as governments, journalists, and writers, thereby infiltrating visual culture to an extent that has not yet been thoroughly examined.

The representational challenge that the oil companies encountered was that their product was crude oil. Sticky, smelly, usually dark black, and inflammable, the substance itself was not an easy or attractive product to display. Oil companies therefore preferred to show "everything except the product," as one industrial photographer pointedly summarized. ${ }^{3}$ In a lecture on "Photography in Industry and Commerce" held in 1961, British photographer and later member of the photography faculty at the Royal College of Art, Michael J. Langford explained what oil companies, who were notorious for their extensive briefs, were looking for:

\footnotetext{
With organizations such as the major oil companies a considerable volume of photography overseas is needed for large-scale internal public relations distribution. On these tours their staff photographers are expected to not only record the company's direct activities but also the way of life of the local peoples and the ways in which oil revenue is improving social conditions. ${ }^{4}$
}

Langford demonstrated that the industrial photographers grasped the complex issue of petroleum's (in)visibility. Besides showcasing the industrial operations, oil companies circumvented the representational ambiguity of oil by diverting the gaze toward "the way of life of the local peoples" and the ways in which oil revenues were "improving social conditions." To do so, the oil industry relied on a visually all-encompassing strategy that involved presenting its direct activities in the oil fields as clean and safe, and moreover it implied representing their activities indirectly by means of scenes far away from the

\footnotetext{
2 Jean-Gabriel Leturcq, "Camera Arabia: An Introduction to the History of Photography in the Arab Peninsula," accessed December 4, 2017, https://leturcq.wordpress.com/2015/10/03/camera-arabia-1/\#comments. ${ }^{3}$ Michael J. Langford, "Photography in Industry and Commerce," Journal of the Royal Society of Arts 109, no. 5061 (1961): 666 (italics in the original).

${ }^{4}$ Ibid., 675-76. In his obituary in The Guardian, Langford he was described as an "influential tutor whose best-selling books became standard texts for generations of photographers." Jenny May, "Obituary: Michael Langford," The Guardian, May 25, 2000, accessed January 30, 2021, https://www.theguardian.com/ news/2000/may/25/guardianobituaries1.
} 
oil fields. These motifs had to convey the impression of social improvement that could be linked to oil revenues, the oil company itself, and the growing reliance on petroleumderived products without ever showing crude oil. Oil companies used photography both to divert the gaze away from petroleum extraction sites and to legitimize their presence by presenting the (positive) socioeconomic outcomes of petro-capitalism for the host country and society at large. In other words, the more Kuwait City made a good impression in such photographs, the better the image different audiences, such as Kuwait's ruler and inhabitants as well as people elsewhere, would have of the company; even if the two things, Kuwait City and the company, were not connected in the sense that the framing of the images insinuated.

The KOC was not the only oil company to rely on professional photographers for their public image. One of the most extraordinary cases-not just in the visual history of oil companies but in the history of corporate industrial photography-is the large photographic public relations campaign initiated by Standard Oil of New Jersey during World War II, around a decade earlier than the KOC's. The example of this photographic campaign underscores the fact that oil companies already considered almost anything to be suitable to represent them photographically, and that they tried to influence public opinion by instrumentalizing a visual medium on a mind-bending scale.

\section{The Photographic Campaign of Standard Oil of New Jersey}

In a 1942 poll, Standard Oil of New Jersey (SONJ), then a major US oil company, was cited as the most disliked firm after a secret 1929 cartel agreement with the German company I.G. Farben became public. ${ }^{5}$ The enterprise decided to hire a public relations consultant with whom they developed "The Standard Oil (New Jersey) Photography Project," which was headed by Roy Stryker. Stryker, an economist and photographer, firmly believed in the power of the photographic medium to alter people's perception-even of SONJ. ${ }^{6}$ The

\footnotetext{
${ }^{5}$ In fact, Standard Oil, SONJ's predecessor, had been the target of anti-monopolistic criticism since the late nineteenth century. This culminated in the court case Standard Oil Co. of New Jersey vs. United States (1911), in which the company was found guilty of monopolizing the petroleum industry through anti-competitive actions. The company was subsequently split into thirty-four competing firms, one of which became SONJ. Given the continuity in the name, SONJ did not possess a blank record in public opinion.

${ }^{6}$ Previously, in the 1930s, Roy Stryker had worked with a team of skilled photographers for the Resettlement Administration and later the Farm Security Administration on a project to document government efforts of fighting rural poverty. The public success of the project encouraged the management of SONJ to undertake a similar public relations campaign directed by Stryker. Cornell Capa, "Foreword, ” in Steven W. Plattner, ed., The Standard Oil (New Jersey) Photography Project (Austin: University of Texas Press, 1983), published in conjunction with the exhibition Roy Stryker: U.S.A, 1943-1950 presented at the International Center of Photography, New York, 7.
} 
campaign specifically targeted white-collar, art-appreciating "thought leaders," a group of people that had been identified as most influential in opposing the oil company. ${ }^{7}$

Between 1943 and 1950, a group of permanently-employed SONJ photographers were sent out to take photographs. An objective, socially aware, and documentary style became the common denominator of practice, as Stryker was convinced that documentary photography with a visually conveyed narrative and a focus on the human element would appeal to the target audience. ${ }^{8}$ Otherwise the photographers enjoyed great freedom in the selection of their motifs and the motifs' level of immediate connection with the oil industry. Project photographer Esther Bubley, for instance, explained, "Any way you could connect something to oil-that for Roy was a good enough excuse to photograph it. You could photograph anything having to do with oil."9 Her colleague Russell Lee remembered the brief as anything to do with grease. ${ }^{10}$ Basically, the goal was to shoot motifs and scenes that documented the "thriving producers and consumers of oil," meaning the modes of production and ways of living that oil enabled and petro-capitalism encouraged. ${ }^{11}$ This very wide brief, the creative freedom, the high level of productivity over a seven-year term, the large geographic coverage, and the multitude of excellent photographic voices who took part were aspects that made SONJ's photo campaign so extraordinary.

The photographers generally captured the impact of petroleum at large, picturing bus stops (as an example of motorization thriving on fossil fuels), large transportations networks, oil tanker manufacturers, petrol stations, oilmen at work, in bars and restaurants, oil towns, agricultural landscapes using synthetic fertilizer, and common ways of living in the mid-twentieth century that were at first glance not obvious spheres of petro-influence and yet somewhat driven by fossil fuels and petroleum-derived products.

Apart from the few series shot abroad (for example in Saudi Arabia and Venezuela), most photos were taken in one of the many oil-producing and oil-refining US states, often in rural areas and small or medium-sized towns within the US. The survey therefore documented the oil industry's substantial share in the national economy and substantiated

\footnotetext{
7 Public discontent was especially large because the agreement had hindered American industry from inventing synthetic rubber, thereby giving Nazi Germany a strategic lead in the war. A subsequent public opinion survey revealed that well-educated, intellectual "thought leaders" in particular were opposing Standard Oil. See ibid., 12-13.

${ }^{8}$ Ibid., 17. Hurley notes that "oil was always in the story, but under Stryker's direction, the emphasis was often on the people who drilled for it or transported it or sold it or used it." F. Jack Hurley, Industry and the Photographic Image: 153 Great Prints from 1850 to the Present (Rochester: George Eastman House, 1980), published in conjunction with an exhibition at George Eastman House, Rochester, in 1976, 101-2.

9 Plattner, The Standard Oil (New Jersey) Photography Project, 20.

10 Ibid.

${ }^{11}$ Ibid., 22. Among the staff photographers were Esther Bubley, John Collier Jr., Harold Corsini, Arnold Eagle, Russell Lee, Sol Libsohn, Gordon Parks, Edwin and Louise Rosskam, Charles E. Rotkin (as the aerial photographer), John Vachon, and Todd Webb.
} 
the way in which oil consumption was even already nested in remote, rural areas, instead of tracing petroleum's rather obvious influence on urban life.

Showing the total infiltration of petroleum into modern life by photographically documenting everyday life as such was nothing less than visionary. Photographs that conveyed a vague connection to oil and carried the SONJ credit line held the most potential to catch the attention of viewers intent on finding the connection to petroleum that the pictures supposedly portrayed. As a result, the petro-intimacy insinuated in the images became normalized as a part of everyday life. But, as visual sociologist Douglas Harper points out, it was also "ironic" that, "because oil was in one way or another everywhere, the photographers were able to photograph virtually anything of a social nature." ${ }^{12}$ In retrospect, the Standard Oil of New Jersey Photography Project was the first deliberate large-scale photographic investigation of petro-modernity at play. Its scope of almost sixty-seven thousand large-format black-and-white photographs and around one thousand color slides of (mostly) American life is photographic evidence of the way that “'oil seeped into every joint' of an increasingly technological nation." ${ }^{13}$

The sobering realization that oil was everywhere also underscored something else: the petro-corporate infiltration of everyday life in the mid-twentieth century. The Photographic Project reflected "the first major, long-range attempt by an industry to justify its role in society through visuals as well as written means." ${ }^{14}$ As such, SONJ not only presented its operations across the US but proudly pictured US lifestyles as being entirely dependent on the oil industry. Although the campaign had been aimed at dispelling public reproaches of monopolization, its photographic evidence instead cemented the involvement of petrocorporations such as SONJ in daily life as inescapable.

Despite these photographic efforts, according to a public poll, SONJ's reputation had not changed sufficiently by 1948. Moreover, because the effect of the photographic campaign could not be measured, the project was cut back and eventually stopped in 1950 . Another reason for the discontinuance was that although the SONJ photographs had been made freely available on the condition that the SONJ credit line was included, magazines and newspapers did not show the expected interest in using the photographs and thereby popularizing the oil company's photographic framing of the world. ${ }^{15}$ Nevertheless, SONJ's

${ }_{12}$ Douglas A. Harper, Changing Works: Visions of a Lost Agriculture (Chicago: University of Chicago Press, 2001), 10.

${ }_{13}$ Plattner, The Standard Oil (New Jersey) Photography Project, 11. Numbers taken from Harper, Changing Works, 12.

${ }_{14}$ Hurley, Industry and the Photographic Image, 101-2.

${ }^{15}$ A small number of photographs from the project were printed in magazines like Life, Look, and Fortune. For example, see “A Portrait of Oil-Unretouched," Fortune, September 1948, accessed January 30, 2021, http://fortune.com/1948/09/01/standard-oil-photos-1948/. The main benefactors, however, were the company's in-house publication The Lamp and school textbooks. See Harper, Changing Works, 12; Hurley, Industry and the Photographic Image, 102. The impact of SONJ's photographs in official learning material on American society is yet to be comprehensively researched. 
Photographic Project demonstrated that, as early as the 1940s, visually representing the oil industry meant shooting "almost everything except the product." 16

The Kuwait Oil Company launched its photographic campaign six years after that of SONJ ended. Given a lack of archival evidence, it remains unclear whether and to what extent the KOC was informed or influenced by the American oil company's program. Considering the long duration and scope of the campaign and the interconnectedness of the global oil sector (the KOC was half-British, half-US owned at the time), officials at the KOC were most likely aware of the project. Besides, since 1948, Standard Oil of New Jersey (today ExxonMobil) owned 30 percent of the Arabian-American Oil Company (ARAMCO) in Saudi Arabia and hence held a foothold in one of Kuwait's neighboring countries. Members of SONJ's Public Relations Department also visited Kuwait and the KOC in spring $1958 .{ }^{17}$ Irrespective of whether a direct connection existed, the KOC's photographic scope turned out to be equally all-encompassing and yet also much more specific, given its focus on a single country.

If "almost everything except the product" was used by oil companies to campaign for a (positive) public image, what creative choices did the Kuwait Oil Company make in the 1950s? The booklet The Story of Kuwait was the first thing the KOC published to introduce a larger readership to (its operations in) Kuwait; it was made available even before the first shipment of Kuwaiti oil had left the country. ${ }^{18}$ Here, the KOC framed Kuwait's history and its own operations through text and, later, especially through photographic representations of Kuwait City that can be summarized and characterized by the metaphor of "making the desert bloom."

\subsection{The Story of Kuwait: Making the Desert Bloom}

Published between circa 1945 and 1963, The Story of Kuwait was the prime print publication that communicated the KOC's narrative of Kuwait's past and present in text and images, which initially addressed an English-speaking audience only. In The Story of Kuwait, textual material and visual images played a crucial role in presenting the oil company's operations and the country's transformation as interdependent success stories of petro-modernity.

\footnotetext{
${ }^{16}$ Langford, "Photography in Industry and Commerce," 666 (italics in the original).

${ }_{17}$ Kuwait Oil Company, Town Office monthly report, March 1958, Town Office, 1957-1958.

${ }_{18}$ For a discussion on the iconography of oil in popular science books titled The Story of Oil and often published by oil companies, see Laura Hindelang, "Oil Media: Changing Portraits of Petroleum in Visual Culture Between the US, Kuwait, and Switzerland," Centaurus 63, no. 4 (2021), doi:10.1111/1600-0498.12418.
} 


\section{The Petroleum Promise}

To shape the way in which oil (production) was perceived, the KOC thought it useful to provide information about Kuwait at least one year before the first oil shipment in 1946. But rather than including primarily information on the oil company, the booklet presented a short account of Kuwait's (pre-)oil history with hardly any reference to the KOC. Spread across twelve pages and without any illustrations, the content of the first small publication focused on the period from 1716, generally considered the founding date of modern Kuwait, until about 1945. As indicated on the booklet's title page, the text was based on an article by Laurence Lockhart (fig. 4.1). ${ }^{19}$ At the time, Lockhart, a scholar of Iran, was working for the Anglo-Iranian Oil Company (AIOC), one of the KOC's 50-percent-shareholders. Lockhart was not only a knowledgeable scholar and oilman but also experienced in writing the company history of the AIOC. ${ }^{20}$ Hence, he likely appeared as the perfect man for developing a (hi)story of Kuwait in accordance with the oil company's interests.

The resulting first issue of The Story of Kuwait appeared in most parts as a brief and somewhat factual historical overview on Kuwait for a lay audience. Without mentioning the oil company, the text affectively framed petroleum as a harbinger of change and prosperity. This represents a classic case of evoking the petroleum promise in anticipation of oil production, and was a narrative that later issues continued to use in order to justify the oil company's operations in the country.

In the opening paragraph of the first issue, Kuwait is carefully situated within the larger geographical and historical context of the Persian Gulf:

The present Arab Shaikhdom of Kuwait has a history of only some two hundred years. But the part of the world in which it is situated has history in every stone, going back over thousands of years to the very birth of human civilisation. The 6,500 square miles of territory that make up the modern state of Kuwait may have formed part of the Garden of Eden, if that delectable spot ever had a precise location on earth. Certainly in the days of the Babylonian and Sumerian Empires, six or seven thousand years ago, this part of the Middle East was no desert, but a fertile plain well capable

\footnotetext{
19 Kuwait Oil Company, The Story of Kuwait (London: Kuwait Oil Company, [ca. 1945]). Lockhart (1890-1975) published exactly one article on Kuwait: Laurence Lockhart, "Outline of the History of Kuwait," Journal of the Royal Central Asian Society 34, no. 3-4 (1947). It is unclear whether Lockhart is the author of The Story of Kuwait or whether he only delivered the historical information, as the journal article and the KOC publication differ strongly in tone and choice of words. While the journal article mentions the first oil shipment in June 1946, the company publication does not include this historic event. Therefore, the KOC booklet was presumably published prior to June 1946. Content-wise it foreshadows Lockhart's article, which was published later, in the July-October issue in 1947, although the KOC text is much shorter, includes fewer details, and was (re)written for a non-academic audience.

20 "One of his most engaging duties at the company was apparently his assignment to write a history of the company for private circulation. This work became the basis for several later official histories of British Petroleum.” Ernest Tucker, “Lockhart, Laurence," Encyclopcedia Iranica Online, May 24, 2013, accessed January 30 , 2021, http://www.iranicaonline.org/articles/lockhart-laurence.
} 


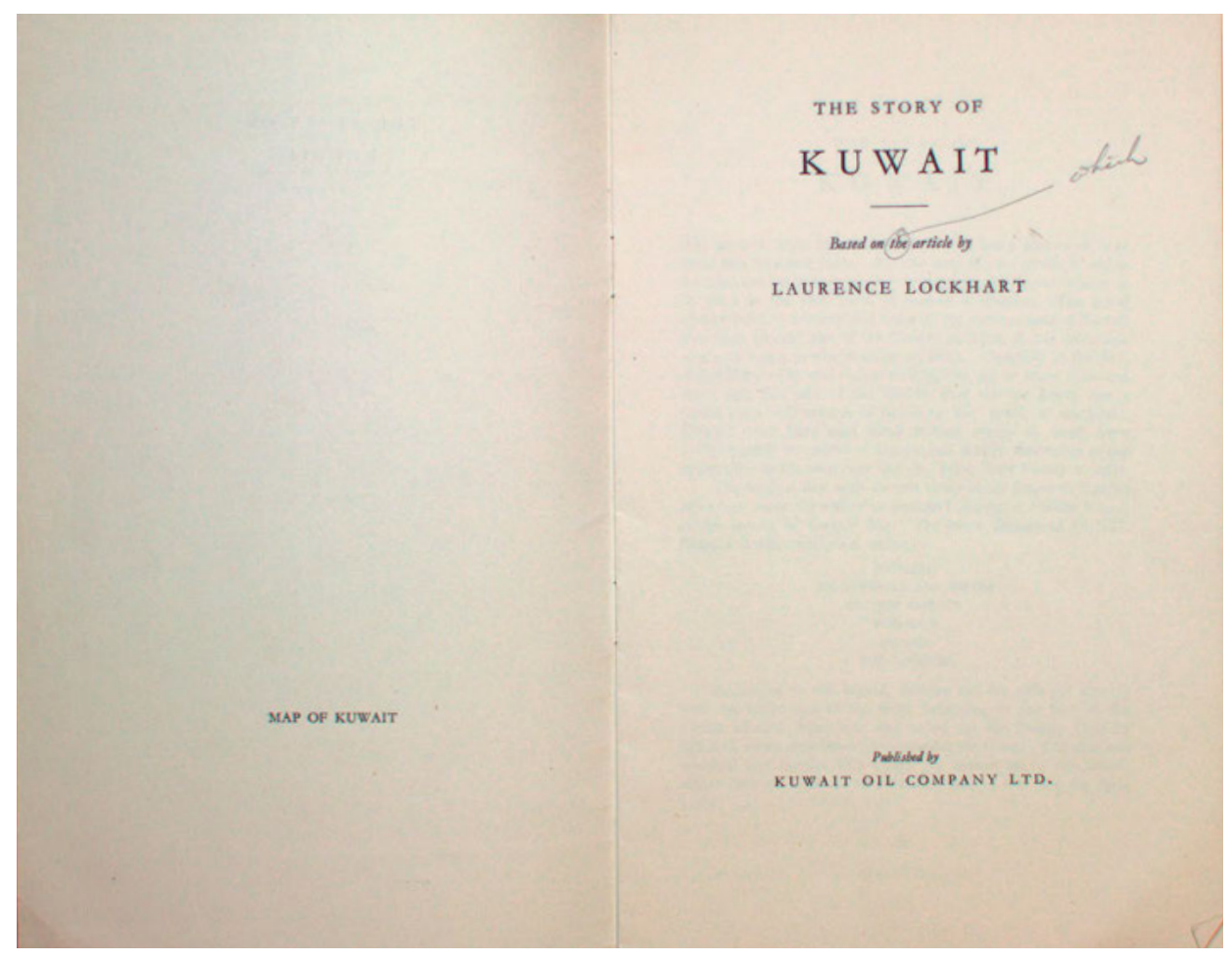

4.1 Title page of The Story of Kuwait (ca. 1945).

of becoming the "cradle of mankind". Kuwait must have seen some stirring events in those days. Unfortunately no record of them exists, though excavation of the many sites in the area may one day bring their history to light. ${ }^{21}$

This paragraph casts Kuwait as part of the great pre-Islamic empires of the Fertile Crescent in the past simply due to its geographical location. The text triggers the reader's imagination to vividly picture this historical Kuwait as a prosperous, civilizational haven, a part of "the Garden of Eden," not a "desert, but a fertile plain." These tropes draw legitimacy from pre-modern history and ancient "golden days" in order to construct an emotionally stimulating national historiography. In this way the text resembles accounts of Iraq written at the time that similarly drew on its Mesopotamian heritage (often with a certain disregard for the present). In the case of Kuwait, the lack of archaeological evidence is conveniently overlooked. The opening paragraph of the first Story of Kuwait establishes a very particular tone of excitement by evoking past glories and implicitly luring the

${ }^{21}$ Kuwait Oil Company, The Story of Kuwait, 1. 
reader to discover and mentally excavate Kuwait's past, all with the vague allusion to the reawakening that Kuwait could be capable of or might even be (historically) entitled to.

The text continues with a short account of Kuwait's history up until 1945 that is fairly in line with basic uncritical versions of the country's history existing today. Finally, the text ends with the promise of petroleum, which was recently discovered in the desert at Burgan. Even though the first export of oil had not yet taken place, it underscores "the new prosperity and promising future brought to the area by the oil fields." 22 The implicit message of the text is that Kuwait's alleged past glories and civilizational potency ("prosperity") will be renewed through the discovery of petroleum, the black gold of the present day. Oil therefore becomes the magically potent substance that can restore Kuwait's importance within the region and offer a life in abundance ("promising future"), an image not too far away from the idea of the Garden of Eden. The Story of Kuwait's authoritative voice of history distracts from its real intention of establishing high hopes and excitement toward the discovery of petroleum. Without even having to mention the KOC, this narrative served to legitimize the oil company's operations as a "petroleum promise" by planting the image of Kuwait becoming a blossoming desert in the reader's mind.

\section{Timelessness, Emptiness, and (Flood)Lights}

Apart from The Story of Kuwait, other articles and book publications of the 1940s and early 1950s that discussed Kuwait also established a strong dichotomy between pre-oil Kuwait and oil Kuwait in anticipation of the petroleum production. In many of these narratives, metaphors of light emerged as the symbol of transitioning from one phase to the other.

One of the first richly illustrated photojournalistic articles on Kuwait was published in Picture Post in July 1946, shortly before the first oil shipment commenced. ${ }^{23}$ Titled "The Mysterious Land of Kuwait," the article characterized pre-oil Kuwait as standing still in time, both in terms of economic productivity and social progress. To the author, the coastal town represented a "timeless, mouldering East," where "everything seems sleepy." ${ }^{24}$ In contrast, the prospect of oil production in Kuwait was heralded as a break away from pre-oil timelessness. "Now big oilfields are opening up... . The rush of modern times is about to overtake Kuwait." ${ }^{25}$ Petroleum was portrayed as a game-changer that would connect Kuwait to an international, homogenous experience of time.

Notions of pre-oil timelessness and standstill were often paired with a narrative of emptiness; this could be framed as not having a long (urban) history or a noteworthy

\footnotetext{
${ }^{22}$ Ibid., 12.

${ }_{23}$ "The Mysterious Land of Kuwait."

${ }^{24}$ Ibid., 13-14.

${ }^{25}$ Ibid., 13.
} 
4.2 Black-and-white photograph of Kuwait Town as published in Picture Post, July 1946. Photograph by N. Tim Gidal.

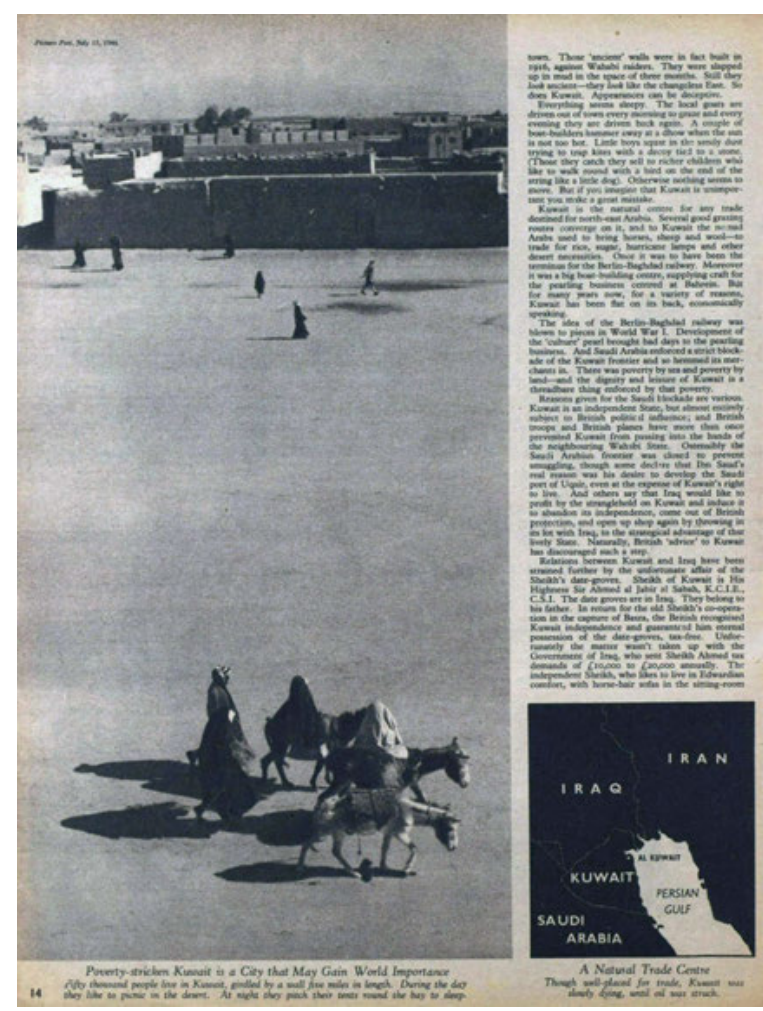

(architectural) appearance, or, generally, being in an unimportant location. A metaphor that was frequently applied in connection with such ascriptions was that Kuwait was "built on sand." A prominent black-and-white photograph in the Picture Post article encapsulated this notion of empty space (fig. 4.2). The photograph is taken from an elevated position, maybe looking from the town wall onto the coastal settlement. Open, void space, in which there are only some people walking or riding a donkey, takes up two thirds of the image. In the background, mud-brick housing emerges as a dense fortresslike entity. The picture creates a strong sense of an almost-deserted town.

Beyond such visual representations, descriptions such as "mysterious" and "obscure" also expressed and perpetuated the exoticization and othering of Kuwait. These attributions conveyed notions of Kuwait as a remote location (in relation to Europe or the US), of being unknown in the international arena, and of being hidden in darkness. In sharp contrast, as another article concluded, the impact of the oil production on this "obscure" location was like "floodlights [that] turn the desert night into day." ${ }^{26}$ Petroleum was portrayed as vital for Kuwait to gain a new visibility. As light also stands for the sun

${ }^{26}$ Case, "Boom Time in Kuwait," 784. 


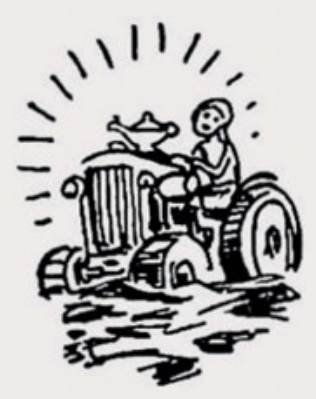

4.3 Illustration by Hakon Mielche in the margins of his Lands of Aladdin (1955).

and thus for the power to make things grow and change, the light metaphors not only resonate with visibility and vision but with growth, life, movement, mobility, and progress. ${ }^{27}$ Switching on the (electric) lights, in this context, meant for this town to wake up from its timeless standstill.

Such orientalist imaginations of the Gulf region and the Middle East as "standing still in time" and awaiting awakening have a long history. ${ }^{28}$ Against this background, petroleum's potential for radical (and positive) change became even more exaggerated and reached fantastical dimensions. For example, the oil experience was frequently metaphorized through the story of Aladdin. An excellent example of this is Danish writer Hakon Mielche's Lands of Aladdin, a well-researched, yet humorous travel account of the oil-producing countries of the Persian Gulf published in 1955. To give just a brief idea, in the margins the book contains an illustration that depicts Aladdin, oil lamp in hand, driving a modern tractor across the field (fig. 4.3). ${ }^{29}$ The oil lamp, which depends on, say, kerosene to produce light, symbolizes petroleum, which in turn (as fertilizer and fuel) enables modern agriculture and the growing of crops to flourish. In this image Mielche cleverly captured the fantasies, extravagances, dreams, and hopes conjured up for Western audiences by the clichéd idea of rubbing Aladdin's lamp.

The Kuwait Oil Company drew on such already prevailing metaphors and images of how to frame soon-to-be oil-producing countries in emotionally stimulating narratives, even if The Story of Kuwait appeared as an almost factual account in contrast. For the second issue of the KOC publication, the Kuwait's oil-fueled transformation was demonstrated by showcasing Ahmadi and Kuwait City, and the best medium with which to do so was photography.

\footnotetext{
${ }^{27}$ The metaphor of light as a symbol of both vision and visibility as well as of the power to change landscapes had already played a key role in the advertisements of Hunting Aerosurveys. These advertisements showed floodlights whose beams of light panned over the landscape and transformed unbuilt areas into future settlements.

${ }^{28}$ Tropes such as the timelessness and emptiness of the Middle East were already present in previous centuries. They can be found in biblical pilgrimage travel writing on the Holy Land as well as, later, in Western travel accounts about the untouched nomadic desert life of the Arabian Peninsula. See Billie Melman, "The Middle East/Arabia: 'The Cradle of Islam,' in The Cambridge Companion to Travel Writing, ed. Peter Hulme and Tim Youngs (Cambridge, UK: Cambridge University Press, 2002), 110.

${ }^{29}$ Hakon Mielche, Lands of Aladdin (London: William Hodge, 1955), Marginal drawings and colored photographs by the author. Mielche was an acclaimed travel writer and the book was simultaneously published in Danish (original), English, and German. It was subsequently reprinted in even more languages, testifying to its huge success in Europe.
} 


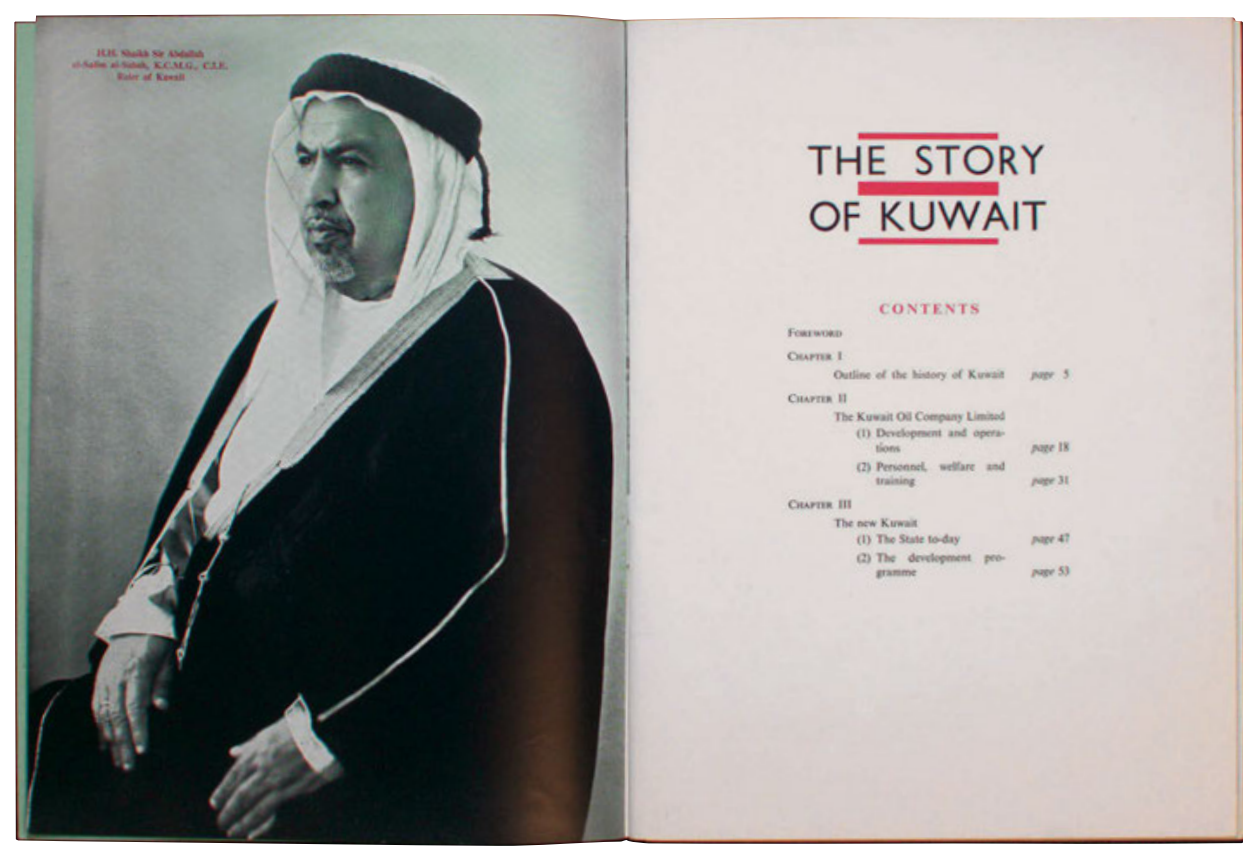

4.4 Frontispiece with a portrait of Shaykh Abdullah and the table of contents of The Story of Kuwait (1955).

\section{Ahmadi and Kuwait City as Showplaces of the Petroleum Promise}

In 1955, the second issue of the KOC publication The Story of Kuwait appeared in a new, richly illustrated format, and with a new three-part structure (fig. 4.4). ${ }^{30}$ Part One contained an "Outline of the History of Kuwait," which was in fact an updated version of the text of the first issue. Part Two was dedicated to a report on the ongoing activities of "The Kuwait Oil Company Ltd" in Ahmadi and its surroundings. Part Three focused on "The New Kuwait," meaning Kuwait City.

In Part One, the brief summary of the history of Kuwait was extended up to 1954. It now included historic moments like the first oil shipment in 1946, and also national political events such as the succession of Shaykh Abdullah in 1950. The section contained portrait photographs of the Al Sabah dynasty as well as black-and-white photographs and drawings of seafaring and shipbuilding and of the pre-oil town. The text used superlatives in abundance to construct a certain Kuwaiti uniqueness linking the "finest pearls" and "the finest harbor" in the pre-oil period to present-day Kuwait as "one of the principal cities in the Arab world." ${ }^{31}$ Responsible for the latter was, according to the text, the

\footnotetext{
${ }^{30}$ Kuwait Oil Company, The Story of Kuwait (London: Kuwait Oil Company, 1955).

${ }^{31}$ Ibid., 14-17.
} 


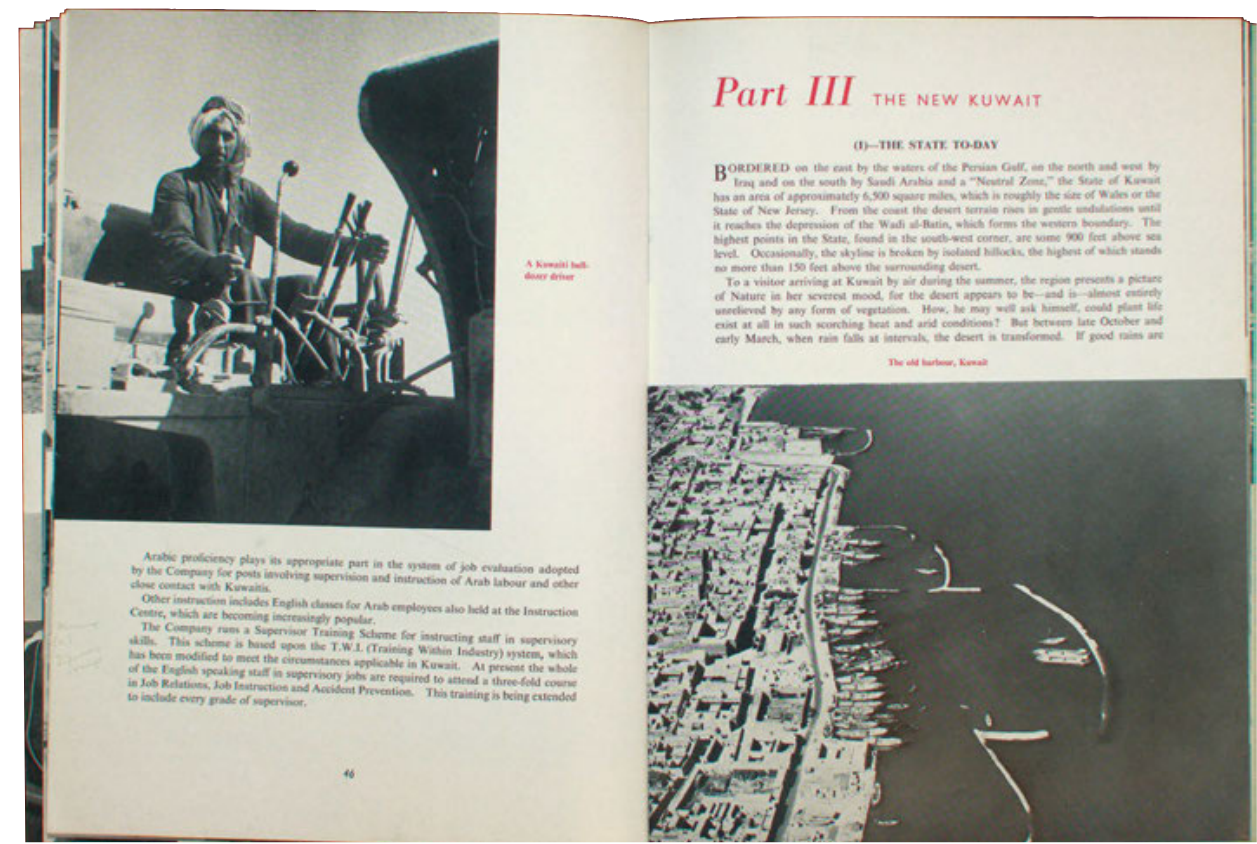

4.5 Oblique of Kuwait's waterfront from the 1951 aerial survey in The Story of Kuwait (1955).

"enlightened policy" of the present ruler, Shaykh Abdullah, and the development program he had launched with the oil revenues, making him "a world-famed figure." 32 Together with the portrait of Abdullah as frontispiece, the booklet affirmed a close alliance between the company and the state of Kuwait through the Al Sabah rulership, a partnership that was indeed crucial for the ongoing state formation. The resulting urban transformation was framed as unique, but also as a natural continuation of Kuwait's rich history (as part of the Garden of Eden, allegedly).

Part Two of the booklet was on the KOC itself, and focused predominantly on life in Ahmadi. It presented a short history of the oil company and a report on the latest achievements, be it new oil infrastructure, the latest statistics of crude oil production, or social facilities for its employees. The accompanying photographs depicted oil derricks, pipeline construction sites, and the oil harbor-basically the whole range of typical oil infrastructure together with photos of employee accommodation and medical and educational facilities. Besides photographs taken at street level, many aerial obliques, presumably taken by the oil company itself, prominently conveyed the spatial expansion of the industry.

32 Ibid., 17. 
Part Three, on "The New Kuwait," was subdivided into two sections. The first section, entitled "The State To-Day," opened with an oblique of the Kuwaiti waterfront from the 1951 aerial survey, given that the aerial view (as shown in the previous chapter) had become the modern representative image formula of Kuwait City despite the increasing outdatedness of the actual photograph (fig. 4.5). The text addressed a reader who was imagined to be arriving in the country by airplane:

To a visitor arriving at Kuwait by air during the summer, the region presents a picture of Nature [sic]
in her severest mood, for the desert appears to be-and is-almost entirely unrelieved by any form
of vegetation. How, he may well ask himself, could plant life exist at all in such scorching heat and
arid conditions? But between late October and early March, when rain falls at intervals, the desert
is transformed. If good rains are experienced, grazing of Beduin [sic] flocks and herds is plentiful,
flowers and plants in great variety make their appearance. ${ }^{33}$

Apparently, the text insinuated, seeing Kuwait from above would present the viewer with the impression of a dust-dry and uninhabitable place, basically anything but welcoming. (To the urban planner, the "void" would have meant space for building, while the visitor was presented as experiencing a horror vacui.) Yet, the 1951 oblique showed a densely built coastal village and its extensive harbor front that did not resonate with the textual account of a deserted place at all. The rest of the section read much like a tourist guidebook. Kuwait's annual, partly more moderate climate, its general geographical features, and its social structure were introduced to the reader in quite favorable terms and these information were complemented by illustrations of people in traditional attire, street views of shops and vendors, an older mosque, and the Public Security headquarters at Safat Square that spoke more or less to the Western imaginary of a pre-oil Arab town.

The second section, entitled "The Development Programme," however, focused on entirely different aspects. Here, the text highlighted progress in the fields of education, medicine, industry, and urban planning in Kuwait City and suddenly the photographic language had changed. The section began by stating:

\footnotetext{
Kuwait to-day is a prosperous and thriving territory under the wise and progressive government of its Ruler ... The Ruler's policy is to use the large revenues accruing from the production of oil for the social and economic development of the territory on up-to-date lines, while at the same time preserving the traditional Arab and Moslem character of the community. ${ }^{34}$
}

The 1955 text therefore suggested that "the new prosperity and promising future brought to the area by the oil fields" foretold in the previous issue of The Story of Kuwait was already happening. While the oil company relied on the figure of Shaykh Abdullah to shower Kuwaiti society with oil revenues, it was clear that the KOC presented itself as responsible for producing the oil monies in the first place.

\footnotetext{
33 Ibid., 47-48.
}

${ }^{34}$ Ibid., 53. 


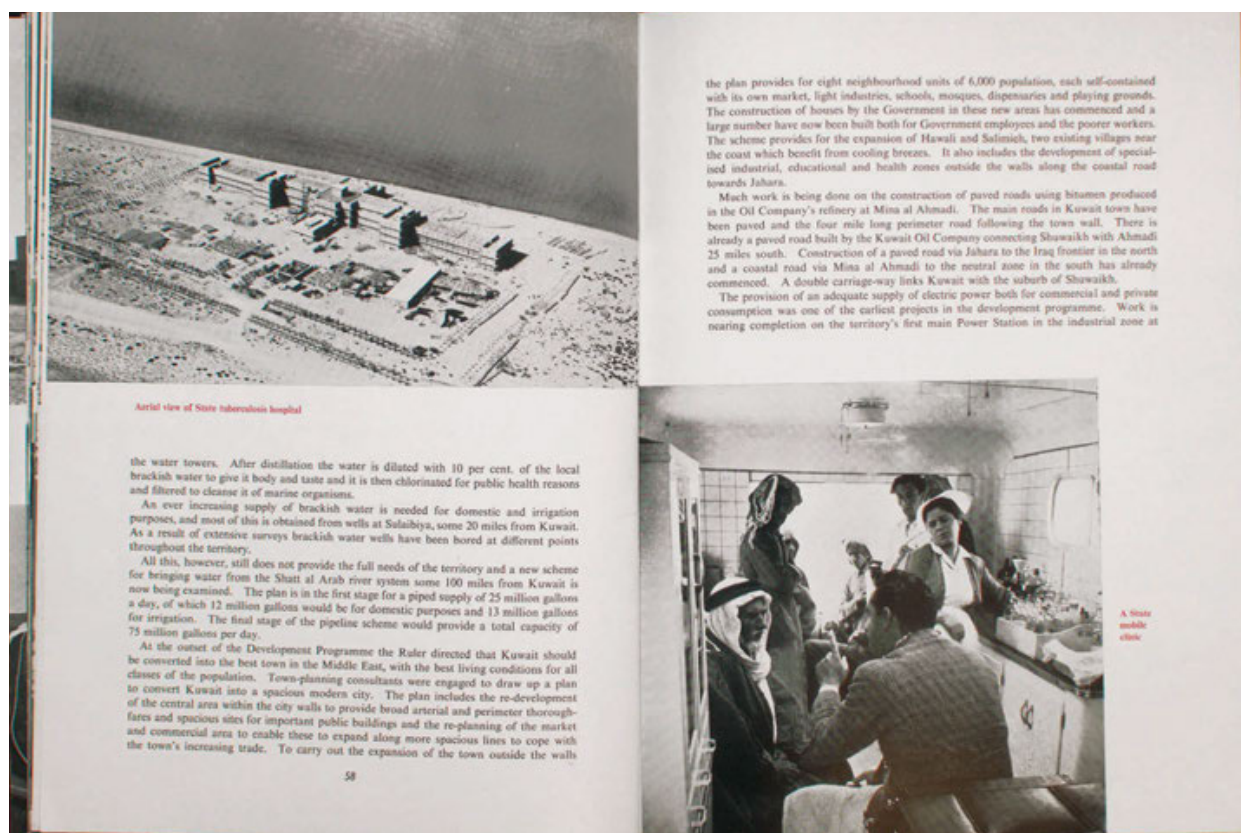

4.6 Aerial view of the state tuberculosis clinic and a state mobile clinic in The Story of Kuwait (1955).

In addition to a biology classroom and the inside of a mobile clinic, the selection of photographic illustrations included with the text showed large, recently erected buildings like schools, the desalination plant, hospitals as well as infrastructure like road networks that were still under construction (fig. 4.6). The preferred form of visual representation were up-to-date obliques that the KOC had photographed itself, for which the popularity of this visualization is underlined. Taken at different heights, the aerials clearly conveyed that the buildings were built somewhere in the desert, surrounded by the barren nothingness that the introductory paragraph had described for which they appeared almost monumental. These were also the photographs that would confront and thwart obliques from the by now outdated 1951 aerial survey that were still used to picture the town as "problematic" urban fabric.

In this section of Part Three, the message was that, with oil revenues, one could build even in the desert. Infused with the dominant logic of modernization theory, subsequent passages read like a modern fairy-tale miracle: "The sudden rise to fortune of Kuwait is bringing about a complete transformation of this territory." ${ }^{35}$ While not stated explicitly in the text, the photographic illustrations clearly suggested that the oil company's

35 Ibid., 53. 
achievement in Kuwait was best measured by Ahmadi's development and Kuwait City's urban transformation.

In the third and final part of the second issue of The Story of Kuwait, the urban development of Kuwait City is presented as dependent on petroleum in multifold ways. The text emphasized that natural waste gas from the oil fields was used to power the massive desalination and electricity plant at low cost and that bitumen produced at the refinery in Mina al-Ahmadi was used to pave roads throughout the city. Mobility was becoming motorized, and any required products could simply be imported by plane or diesel-powered ship. However, part and parcel of modernization, the publication suggested, was not just the production but also the consumption of petroleum. The road to modernity implied total immersion in petroleum, either directly or indirectly, and with it immersion in the urban visual culture of petro-modernity.

With the 1955 issue, the KOC publication merged corporate and national narratives, portraying the history of a country through the (visual) lens of the company. The photographic showcasing of the "development" in both Ahmadi and Kuwait City served to legitimize the company's operations and the need for both oil revenues and petroleum. Up-to-date photographs of new architecture, infrastructure, and mobility delivered evidence of the change taking place under the influx of oil revenues and oil-derived products. By devoting a whole chapter to Kuwait City in the corporate publication, the KOC not only claimed authority over the oilfields and over the company town Ahmadi, but also claimed credit for the ongoing urban transformation of the city-state itself. One could say that the KOC aimed at an all-encompassing scope of motifs similar to SONJ's, yet it focused exclusively on the country of Kuwait. Just as Michael J. Langford had outlined, the KOC's (photographic) self-portrait The Story of Kuwait not only presented "the way of life of the local peoples" (both employees of the KOC and residents of the capital), but also showed how oil revenues were "improving social conditions" in the country. However, not everybody believed the Kuwait Oil Company to be of benefit to Kuwaiti society, as the company came to experience in the following years.

\subsection{Persuasion and Ambiguity in Color}

\section{The Oil Company's Image Crisis}

The 1950s in the Arab world were characterized by, among other things, rising antiimperialism and Arab nationalism. The generally heated political atmosphere climaxed with the Suez Crisis in 1956-57. These tensions were strongly felt in Kuwait when, in late 1956, several oil wells were sabotaged and Kuwaiti social clubs pressured shop owners to stop serving British and French customers. ${ }^{36}$ In this context, al-Ittihäd, a newspaper

\footnotetext{
36 Town Office, Incidents in Kuwait, November 21, 1956; Report on the cases of sabotage and resulting fire at well no. AH-5 on the night of the December 10, 1956, and following days, December 15, 1956, Kuwait
} 
published by the Federation of Kuwaiti Students in Egypt, and Sabāh al-Khayr, an Egyptian weekly magazine founded in the 1950s and read in Kuwait, identified the Kuwait Oil Company as a harbinger of imperialism in Kuwait.

To advertise the positive impact of the KOC in Kuwait more effectively, the company decided to establish a Town Office in Kuwait City that would coordinate and expand public relation efforts toward a greater Kuwaiti and Arab public. ${ }^{37}$ The office was situated in the Thunayan Al Ghanim Building, which was located at the Jahra Gate roundabout and was one of the most prominent and modern buildings at the time. ${ }^{38}$ In addition to receiving responsibility for most of the KOC's corporate public relations, the department coordinated the official communication with the ruler and the government of Kuwait, and managed all issues regarding Kuwait City. The office also served as the initial point of contact with the company for visitors by providing information and photographs.

One of the new strategies of the Town Office was to place KOC-related articles in Arabic-language Middle Eastern newspapers and magazines "to indicate to the general public the good points of the Company." ${ }^{39}$ The KOC also opened a Display Center in Ahmadi which informed visitors on the oil industry from prospecting to oil-derived products with the help of displays, dioramas, and other text-and-image material and thus served another important outlet to tailor information on petroleum (see fig. 4.19). In February 1957, on the anniversary of the accession of Shaykh Abdullah, the KOC finally released the first issue of its Arabic-language monthly Risālat al-Nafț (Message of Oil), which was intended to instruct, entertain, and inform the Arab employees as well as the Kuwaiti public about the company's activities. ${ }^{40}$ The publication was received with mixed feelings: in a letter to the magazine, one reader sharply critiqued the monthly's second issue from April 1957 for its content, which he considered unsuitable, yet proudly praised

\footnotetext{
Situation in Relation to the Middle East Crisis, file 3 and 6, 1956, 106962, BP Archive, University of Warwick. 37 On the KOC's struggle in Ahmadi to challenge anti-imperialist and nationalist opposition and critique, see also Reem Alissa, "Building for Oil: Corporate Colonialism, Nationalism and Urban Modernity in Ahmadi, 1946-1992” (PhD diss., School of Architecture, University of California, 2012), chapter 3.

${ }_{38}$ Elegantly built over a boomerang-shaped layout, the Thunayan Al Ghanim Building, or the "Rolls Royce Building," was the first multi-story building in Kuwait and allegedly the first building with an elevator that was commonly referred to as "the jumping horse." The building not only housed the KOC Town Office but, over the decades, also the famous Kuwait Bookshop, the first office of Kuwait Airways, the Sultan Gallery, and a Lebanese car wash. Information received on the walking tour "City on Display," organized by Madeenah and led by Deema Alghunaim around Fahad al-Salem Street, February 2, 2018; see also Fabbri, Saragoça and Camacho, Modern Architecture Kuwait, 50-51.

${ }^{39}$ L. Y. Jordan to C. A. P. Southwell, April 16, 1957, Press and Publications 1957: Broadcasting, 106863, BP Archive, University of Warwick.

${ }^{40}$ Arabic Magazine Meeting, April 29, 1957, ibid. Although intended as a monthly periodical, the second issue appeared two months later in April 1957.
} 
"its printing and beautiful production, which out-classed all Arabic magazines issued by other oil companies." ${ }^{41}$

Indeed, the KOC was concerned that its publications "compare favourably in standard of publication and contents with those of neighbouring oil companies," such as the highly regarded Arabic and English magazines produced by ARAMCO. ${ }^{42}$ To do so, the company realized that it needed new and up-to-date photos that would put its corporate narrative into (the right) perspective and eventually commissioned the British industrial photographer Adolf Morath to come to Kuwait in April 1956. ${ }^{43}$ Given the turbulent times, it was no coincidence that a professional photographer who was highly experienced in helping industrial companies improve their reputation was contracted.

\section{The Industrial Photographer Adolf Morath}

Differently than the permanently-employed staff photographer, Adolf Morath (19051977) embodied a new type of famous, artistic, and independent photographer hired for temporary industrial assignments that emerged in the 1950s. ${ }^{44}$ In his function as photographer for mostly British heavy industries, Adolf Morath traveled to Kuwait and other places in which British companies (that had often grown as part of an imperial network) operated with a brief and a time limit and then returned to his London studios to develop, enlarge, and color-enhance the photographs as needed.

Prior to his work in Kuwait, Morath had undertaken substantial pictorial surveys for the British Iron and Steel Federation and the British South Africa Company, which operated copper mines in Northern and Southern Rhodesia (today Zimbabwe and Zambia). He also portrayed several refineries of the AIOC (one of the KOC's shareholders) in England. On behalf of the KOC, Morath came to Kuwait to shoot in Ahmadi, in the oil fields and the refineries, and also in Kuwait City. ${ }^{45}$

\footnotetext{
${ }^{41}$ Anonymous letter to the editor of Risālat al-Nafț regarding issue no. 2 (ca. April 1957 or later), English translation by KOC employees, ibid.

${ }^{42}$ Arabic Magazine Meeting, April 29, 1957, ibid. Even before the publication of Risālat al-Nafț, the Iraq Petroleum Company had started issuing its Arabic-language magazine Ahl al-Naft (People of Oil) and ARAMCO its Qäfilat al-Zayt (Oil Caravan), the Arabic version of the English-language magazine ARAMCO World.

${ }^{43}$ Although the KOC was owned in equal parts by American Gulf Oil and British Petroleum, initially it was BP that took the lead in steering company business, including PR. Rodney Giesler, a British filmmaker who became the director of the Kuwait Oil Company Film Unit in 1958, remembers: "The British side from BP were experienced in PR, and took command of things. There was a power struggle later on when the American interest increased, and they became responsible overall for PR." Giesler, "Memories of Kuwait 1958-1961," file 1/1.

${ }_{44}$ This was the case in Britain as well as in the US; see Hurley, Industry and the Photographic Image, 101.

${ }_{45}$ Practically no documentation on Morath's three Kuwait trips (besides the actual photographs of the trips, held in the oil archives at Warwick and Ahmadi) exists. The exception are three letters, in which Morath mentioned the upcoming assignment with the Kuwait Oil Company and his stay in Kuwait in April 1956
} 
From his first visit in 1956, Morath created five color and three black-and-white photographic albums for the KOC, in which some prints existed in both color schemes. The successful execution of the first commission brought him two subsequent assignments in March 1958 and April 1960, which were then carried out entirely in color. At the time, high-quality color photography-just like multi-color printing-was not common in Kuwait. Most postcards that used photographs, for example, were handcolored. Industrial photographer Michael J. Langford noted in the early sixties that color photography was "still very expensive" and that "its main application these days, in terms of printing, is in internal reports, in illustrations where colour must be used for technical purposes." ${ }^{46}$ The three extensive surveys of Kuwait undertaken by Morath mostly in color therefore reflected a great financial commitment on the side of the KOC. Yet, the majority of the large-format color photographs pictured motifs for which color was not a technical necessity. Instead, color was part of an aesthetic rhetoric used to highlight the petro-fueled change of the urban environment in favor of the oil company.

\section{A Concrete Garden Growing from the Desert}

The KOC immediately used Morath's black-and-white photographs to illustrate the third issue of The Story of Kuwait, which was published in 1957. ${ }^{47}$ Appearing in Part Two on the KOC and its activities in Ahmadi, Morath's photographs highlighted the relationship of the oilmen and their families with the oil company in order to give a more human touch to the industry, showing for instance workers (with family members) in front of newly built company housing, in training sessions, in class, and at the workplace (fig. 4.7). ${ }^{48}$ Here, Morath's longstanding expertise as a portrait photographer before servicing the industry came in handy. Beneath the human element that the pictures were probably to convey, the social and racial hierarchies at play at the KOC were made apparent: Kuwaiti and Arab workers were primarily shown in situations of being provided for, of being taught and

to his former assistant Marietta Schrömbgens. Morath to Schrömbgens, January 23, February 7, and April 2, 1956, Private Collection Marietta Schrömbgens. Unfortunately, there is also no material available on who was in charge of the KOC's photography prior to Morath. A year after Morath's first visit, De Candole argued: "We need a professional photographer. It is very expensive using the services of a man like Morath, and the photographs he took for us last year are already mainly out of date." Yet despite the KOC's continuous reliance on photography for its public relations, for reasons unknown no permanent photographic unit was established and in 1958 and 1960 Adolf Morath was hired again. De Candole to General Manager, April 27, 1957, memorandum, Press and Publications 1957: Broadcasting.

${ }^{46}$ Langford, "Photography in Industry and Commerce," 678.

${ }^{47}$ Kuwait Oil Company, The Story of Kuwait (London: Kuwait Oil Company, 1957).

${ }^{48}$ Morath became famous for a style of industrial (color) photography that conveyed the "human touch" of the industries depicted. For an example of how this angle of his work was received, see for instance "The Snapshot Schoolboy Is Now a Top Photographer," The Bulletin, February 4, 1959, reprint. 


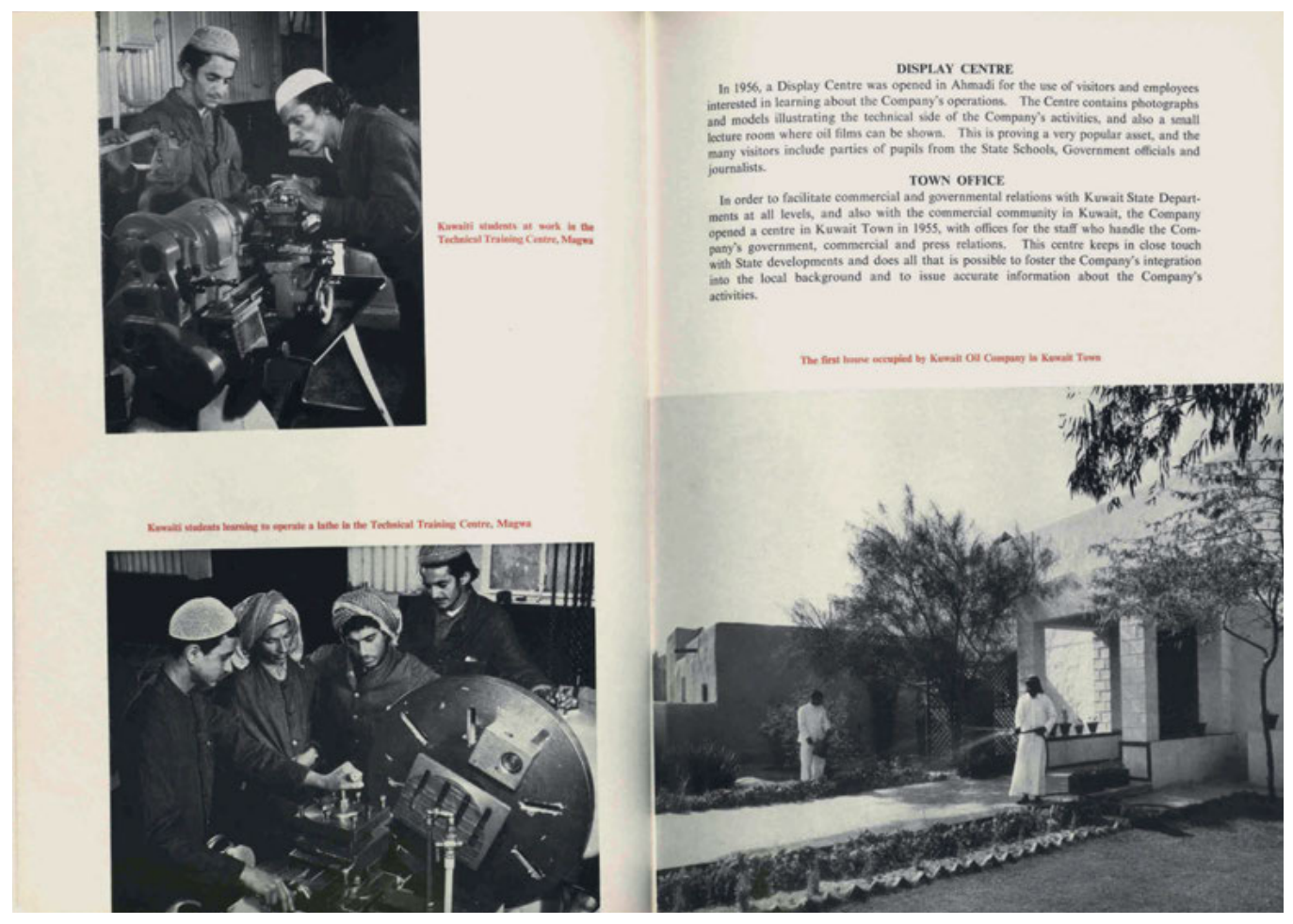

4.7 KOC workers in training and in front of newly built housing, photographed by Adolf Morath and printed in The Story of Kuwait (1957).

trained, often with white, probably British or American instructors, doctors, and teachers there to direct them. ${ }^{49}$

Morath's photographs had also a strong impact in the final part of The Story of Kuwait, the section on the development program of Kuwait City. Here, they replaced two thirds of the previously used photographs. ${ }^{50}$ Technically, the pictures substantiate Morath's excellent knowledge of architectural photography. Set against a wide and cloudless sky, the buildings of Shuwaikh Secondary School, for example, are shot in sharp early morning light (fig. 4.8). Taken slightly from below in order to encompass the entire length of the façade, the photographer portrayed the buildings with enormous horizontal and vertical presence through the use of sidelight. People as "staffage" entering the building increases the impression of massive architectural volume.

${ }^{49}$ On structural hierarchies engrained in the employment and housing policies of the KOC, see Alissa, "Building for Oil," 42-44.

50 This section contained ten images in the 1955 edition and fourteen in the 1957 edition; ten of the images in the 1957 edition were new additions. 


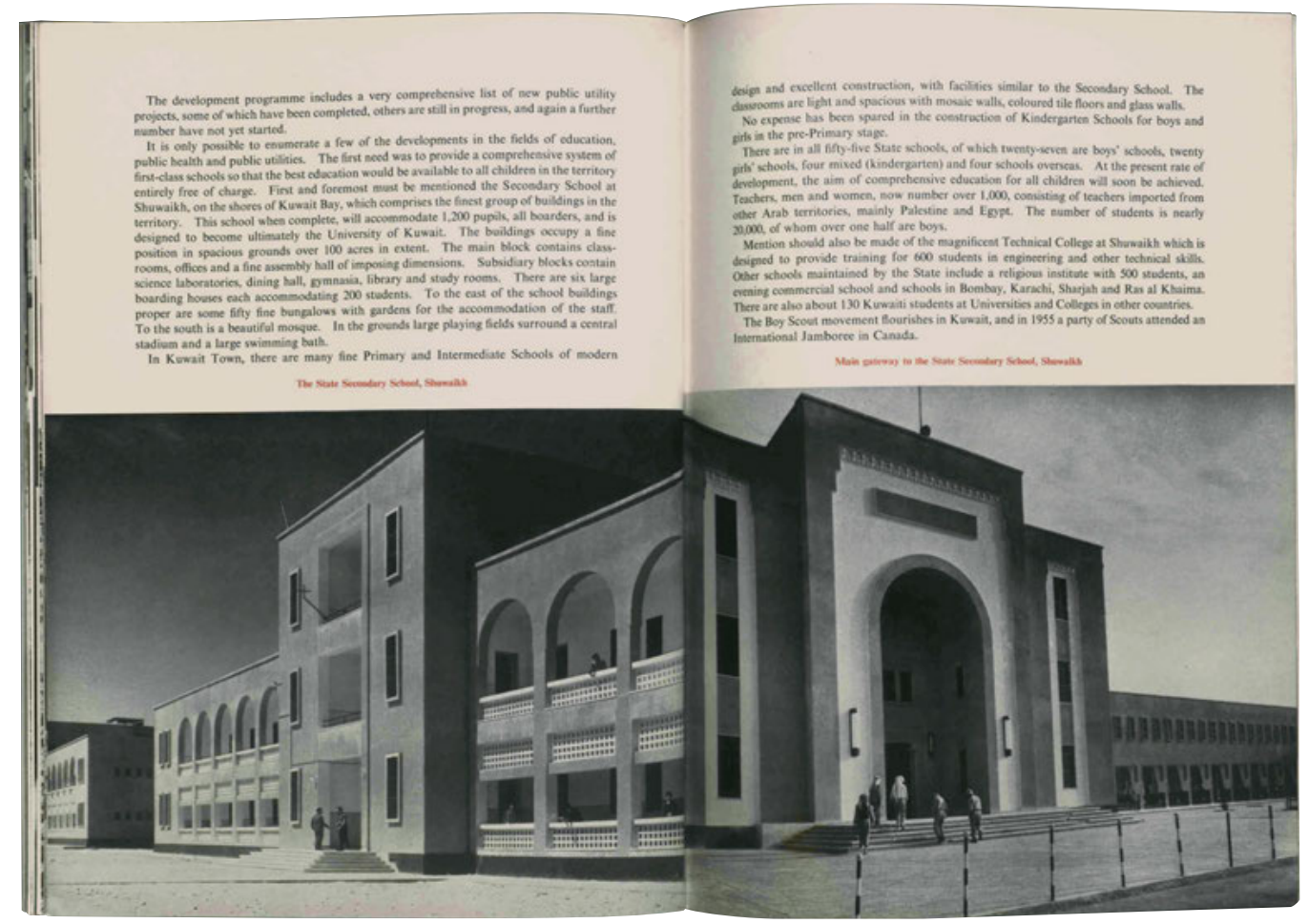

4.8 Shuwaikh Secondary School, photographed by Adolf Morath and printed in The Story of Kuwait (1957).

Other photographs by Morath that were used in this section showed, for example, a new Kuwaiti villa and a new housing estate for middle or lower-income families in Kuwait City (fig. 4.9). The images manifest a similar tension between the horizontal wideangle perspective, which is able to bring more of the surrounding environment into the foreground and background of the image, and the isolation of the buildings through the photographic exclusion of any architectural or urban context. In these pictures, sharp sunlight, a cloudless sky, and a foreground that often consists of loose gravel are strongly evocative of the desert and act as a void against which the new architecture (representing Kuwait City) rises. Resonating with The Story of Oil's foundational metaphor of making the desert bloom, Morath's photographic compositions present the newly built constructions all over Kuwait City as a concrete garden growing from the desert after being watered with petroleum. Depicted mostly at eye level, the photographs taken by Morath delivered visual proof of the petroleum promise on the ground as it happened.

Not only did the KOC meet Morath's photographic approach with approval-a much wider readership also appreciated the third edition of The Story of Kuwait. As an internal report from May 1957 documented, this issue received numerous press reviews 


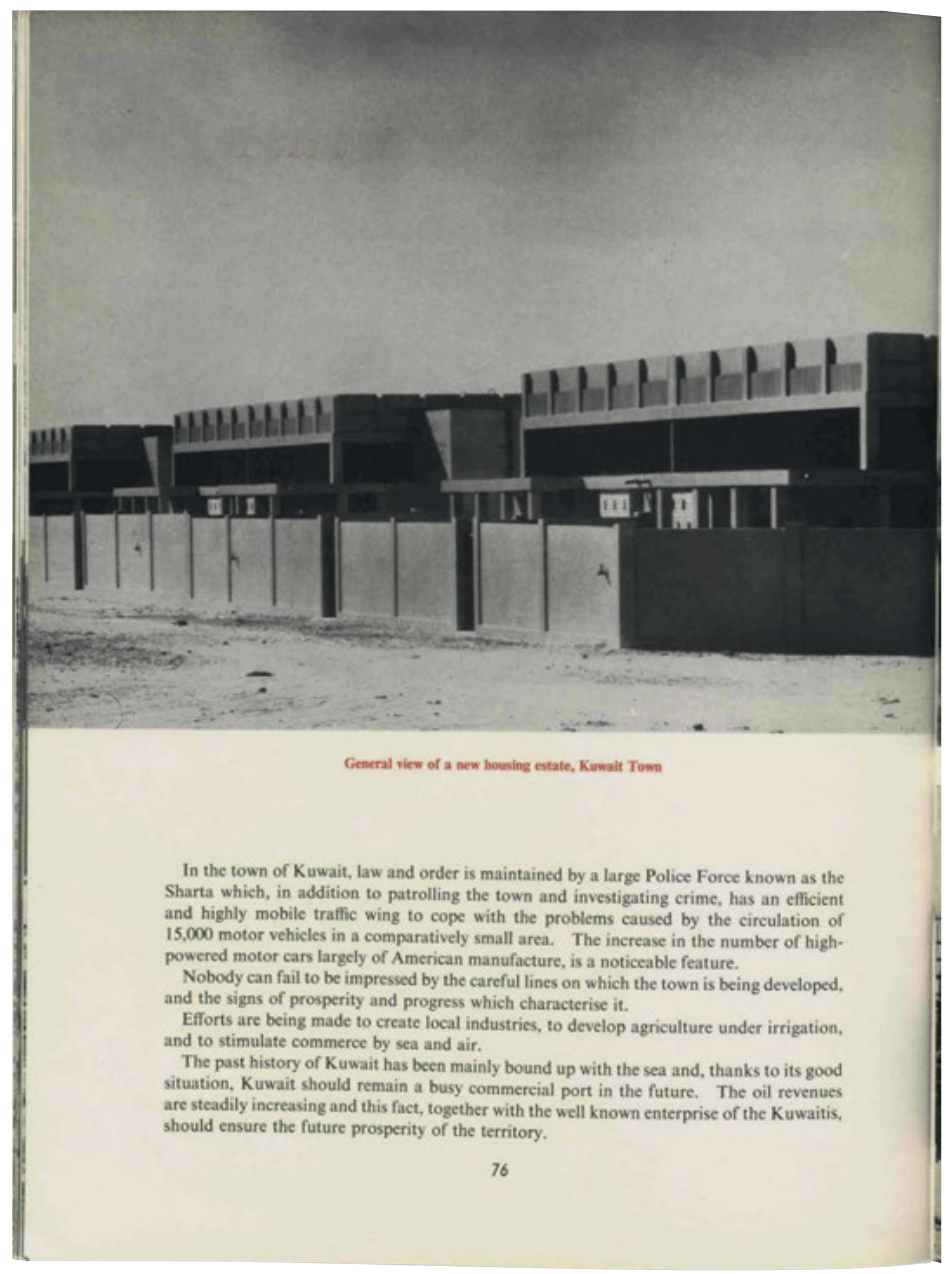

4.9 Housing estate for middle- or lower-income families in Kuwait City, photographed by Adolf Morath and printed in The Story of Kuwait (1957).

that praised the new photographic illustrations. ${ }^{51}$ Among the quoted reviewers were not only specialized journals like the Institute of Petroleum Review and The Oil Engine and Gas Turbine, but also the Financial Times, The Times, and The Iraq Times, which suggests that The Story of Kuwait had a broad circle of notable-English-language-recipients. Moreover, the internal report considered the reproduction of phrases and information

${ }^{51}$ Press review of The Story of Kuwait (1957), May 20, 1957, Press, Broadcasting, papers, 1958-59, 106988, BP Archive, University of Warwick. 
taken from the booklet by other press outlets, such as Kuwait's oil history described as a "unique" experience, as a sign of the publication's persuasiveness and success. ${ }^{52}$

In line with the pressing demand to create more communication with Arabic-speaking audiences, an Arabic version was finally also produced. In March 1958, E. A. V. de Candole, public relations officer and head of the Town Office, reported that

our booklet "The Story of Kuwait" (Arabic and English) has a very wide circulation among Government Departments and Arab visitors to our Display Centre, and we have issued over 1000 copies of the smaller Arabic booklet "Al Naft fi al Kuwait" [Oil in Kuwait] for use in Government schools. I have been complimented by the Ruler and the Director of Education on the suitability of these booklets for educational purposes. ${ }^{53}$

By mid-1958, 5,000 copies of the latest Arabic version of The Story of Kuwait had been ordered, attesting to its success and growing influence. ${ }^{54}$

The illustrated booklet The Story of Kuwait gave the KOC credit as a popular knowledge authority on Kuwait among English- and Arabic-speaking audiences alike. Its textual version of the (hi)story of Kuwait was influential, and the Kuwaiti government even relied on its Arabic material about Kuwait's oil production for educational purposes. The booklet's visual language subtly but effectively insinuated that the oil company's product was not merely crude oil, but rather that the company should be credited with (assisting) Kuwait's urban transformation and social progress, which itself was presented as a unique miracle to make the achievement seem even bigger and somewhat magical. Similarly, Reem Alissa concludes that the KOC's PR campaign directed toward its employees in Ahmadi "successfully used architecture and urban development as a means to legitime itself in order to secure its continued presence." ${ }^{55}$ Morath's color photography, however, was the most persuasive in visualizing the KOC's favorite narratives and they reveal what it meant for the company agents in the mid-twentieth century to engage in petro-modernity.

\section{Kuwait Illuminated}

The color photographs Morath took of Kuwait City and that are today in the company archives conjured up petro-modernity as a colorful, progressive, and dynamic atmosphere, an iridescence that black-and-white photos were simply not able to

52 Ibid.

53 De Candole to Bernard Burrows, Political Resident, Bahrain, March 23, 1958, Town Office, 1957-1958.

${ }^{54}$ Kuwait Oil Company, Town Office monthly report, August 1958, ibid.

${ }_{55}$ Alissa also observed that The Kuwaiti, the English-language bi-weekly company magazine, "shifted its focus from international, British and Ahmadi news to articles which highlighted its contributing role to the architectural, urban and social development [of] Kuwait City, with particular attention to oil wealth's contribution to modern state projects" from 1957 onward. Alissa, "Building for Oil," 84. 


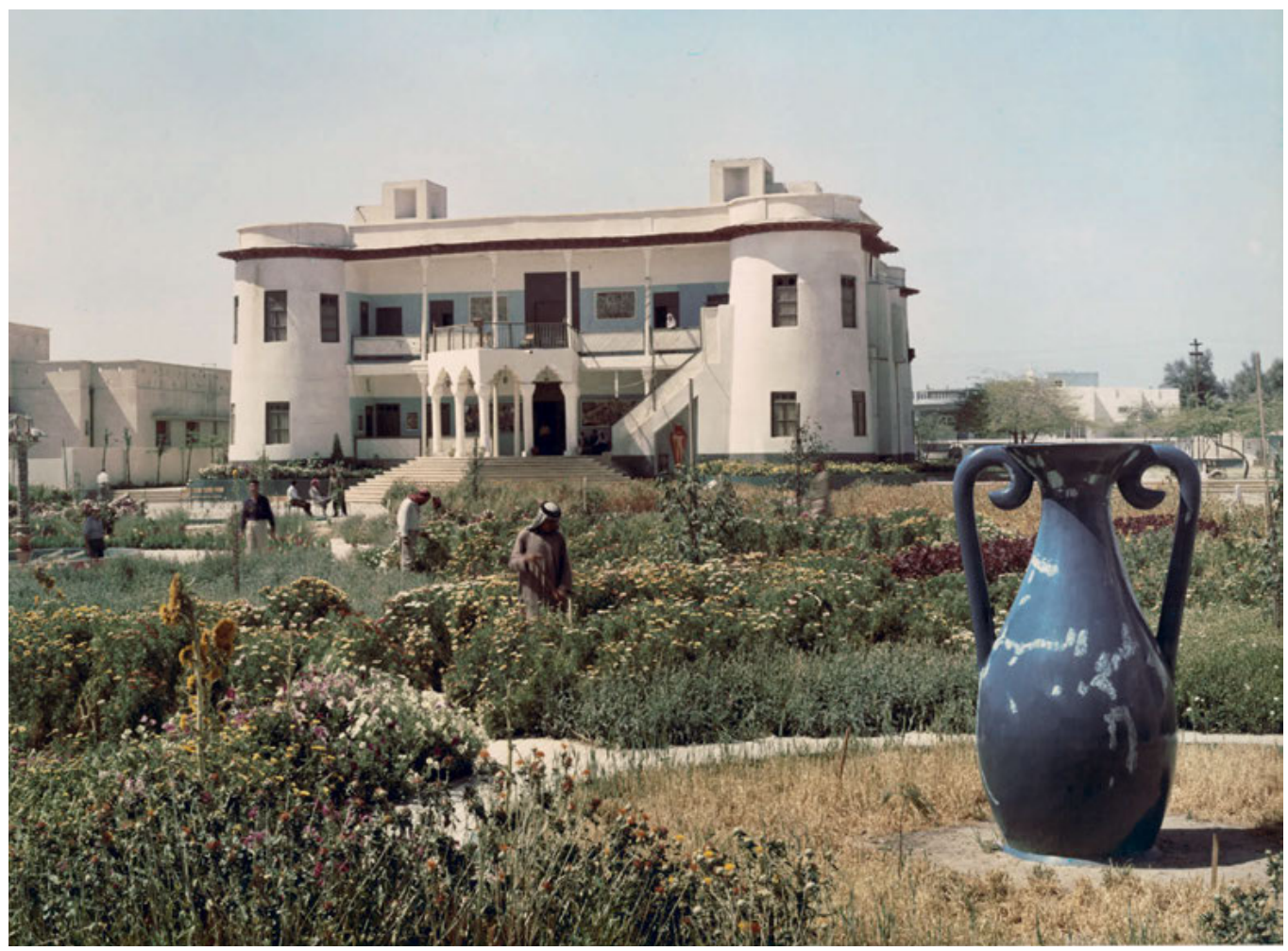

4.10 Adolf Morath, The Museum-Kuwait Town, March 1958. Color photograph.

communicate. Color was undisputedly better equipped to capture the blooming garden that surrounded the recently opened National Museum of Kuwait (fig. 4.10), which was housed in the abandoned diwan of Shaykh Khaz'al of al-Muhammara (today Khorramshahr). ${ }^{56} \mathrm{~A}$ view of the new petrol station just outside the former town wall also projected colorful scenery (fig. 4.11): the steel structure of the petrol station painted with blue and white varnish (almost certainly based on a petroleum derivative); the shiny surfaces of the freshly polished mint-green and red-and-white cars and red lorries that ran on petrol and whose industrial production depended on fossil fuels; and the blue-and-white gasoline pumps with their plastic tank hoses. To better showcase

${ }^{56}$ Shaykh Abdullah initiated the first National Museum in the diwan of Shaykh Khaz'al (1863-1936) in 1957, the former ruler of al-Muhammara, in what is today Khuzestan, Iran. Khaz'al was a close friend of Shaykh Mubarak the Great and frequently stayed in Kuwait in the early twentieth century. See Noura Alsager, ed., Acquiring Modernity (Kuwait: National Council for Culture, Arts and Letters, 2014); Exhibition booklet of the Kuwait Pavilion curated by Alia Farid, published for the 14th International Architecture Exhibition of the Venice Biennale, 5. 


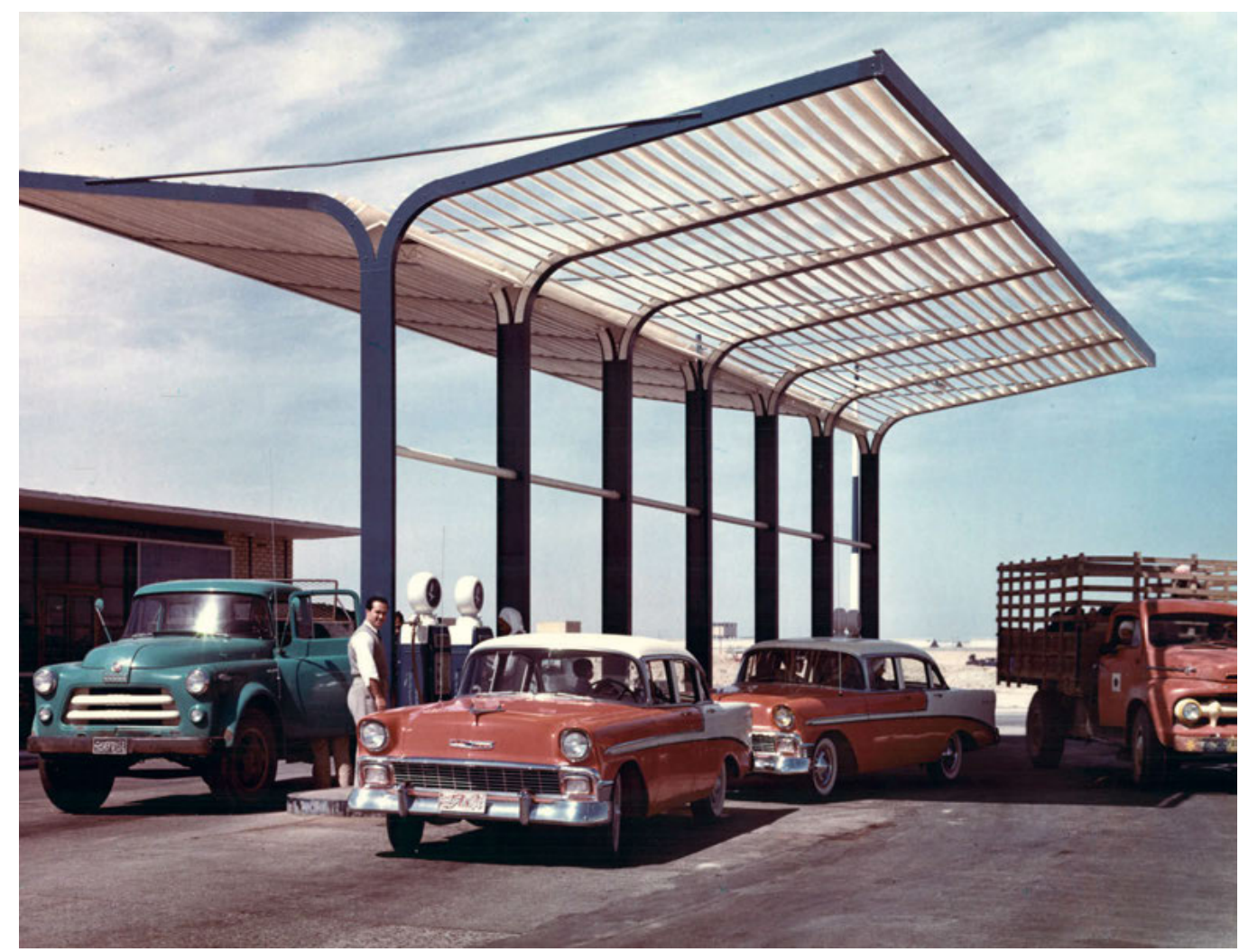

4.11 Adolf Morath, General View of the Petrol Station Outside the Lizard Gate, Kuwait, April 1956. Color photograph.

the petrol station, Morath also relied on a wide foreground (asphalted pavement) and a wide, empty background (desert-like space set against the blue sky) in combination with sidelights. Furthermore, Morath tended to elaborate his compositions not only with human staffage but also with cars. With their bright varnishes and beaming (metal) surfaces that contrasted starkly with the subtle color palette of the bricks, coral stone, and sand of Kuwait's pre-oil habitat, the brand-new cars stood out as both motifs and accessories. For example, a row of parked cars became the visually competing point of contrast in a photograph of the ruler's Seif Palace (fig. 4.12).

The richly saturated colors in the photographic images were vital to highlighting the arrival of petroleum-derived materials and textures previously unknown in such abundance (if at all) in Kuwait. Color allowed the images to create visibility for petroleum-derived, chemically enhanced products like varnish, paint, plastics, and rubber as well as for cues of petro-modernity in the Gulf like motorized mobility (fossil fuels), neon signs (electricity), and lush gardens (desalinated water). Kuwait City 


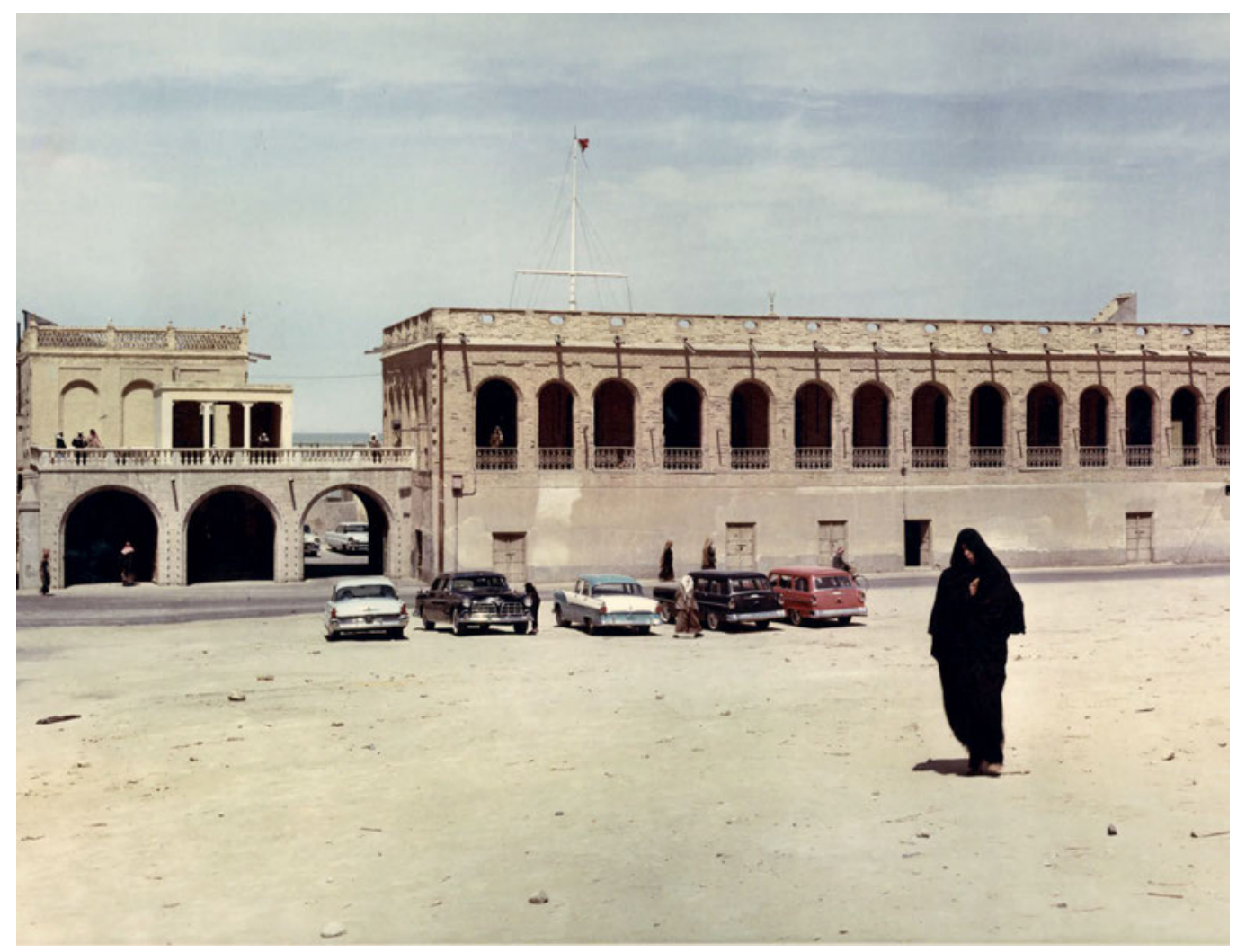

4.12 Adolf Morath, The "Sif" Palace, on the Kuwait Waterfront, April 1956. Color photograph.

emerged as a colorful coral reef from the sandbanks of the Persian Gulf: mesmerizing, constantly growing, and with a swirling dynamic - a grand pearl of intriguing sheen rising amid the sandy dunes. In the context of the medium of photography itself, the color photographs became novel but "authentic" and "realistic" representations of 1950s Kuwait City due to the rather factual, documentary character attributed to the medium at the time.

Of course, Morath's photographic representation of Kuwait City might have exaggerated the positive impression. Yet, accounts of the oil city given in the transregional cultural magazine al-'Arabi also described the urban transformation of Kuwait by the proliferation of color in the previously sand-colored coastal town. In an article titled "Architecture in Kuwait" published in December 1959, the reader was presented with the fact that many façades of newly erected apartment blocks, private villas, and even governmental buildings, like the new municipality, made use of color in combination with pillars, railings, and window mounts in contrasting shades (fig. 4.13). As such they 


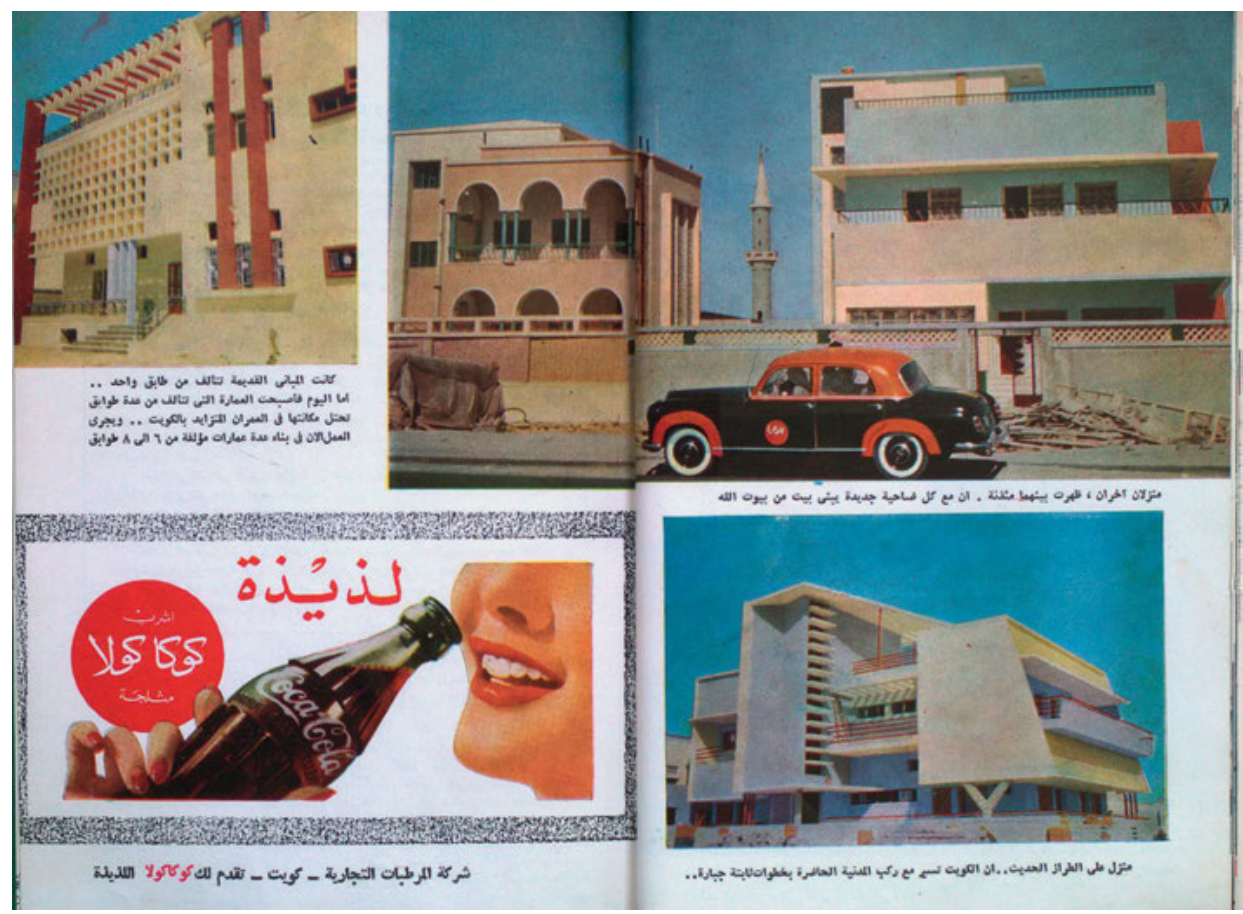

4.13 Spread from al-'Arabī, December 1959, showing new construction and housing projects in Kuwait City in bright colors.

appeared in the color photography of Oscar Mitri, an Egyptian photographer $\left({ }^{\star} 1927\right)$ who had worked for the renown magazines Akhir $S_{\bar{a}}^{c} a$ and al-Mușawar before moving to Kuwait to join $a$ - $^{\prime} A r a b i \overline{~ a s ~ i t s ~ f i r s t ~ l e a d ~ i n-h o u s e ~ p h o t o g r a p h e r . ~}{ }^{57}$ This new appearance of the city in color was amplified by photographs of ample green space, in form of public and private gardens and of tree-lined avenues, such as the first ring road (fig. 4.14). Here, the article noted: "Having sorted out the water issue, starting gardens in Kuwait has begun, and by doing so, the yellow color of sands will be replaced with green." ${ }^{58}$ However, the article made clear that only at nighttime Kuwait City showed its full potential, when the capital became a "river of lights on the Gulf shore":

\footnotetext{
${ }^{57}$ On the history of al-Arabī and in its role in promoting Pan-Arabism, magazine photography, and women, see Bettina Gräf and Laura Hindelang, "The Transregional Illustrated Magazine al-Arabi: Knowledge Production and Cultural Imaginations in the 1950s and 1960s," Middle East Journal of Culture and Communication (forthcoming 2022).

58 "Al-'Imāra bi-l-Kuwayt [Architecture in Kuwait]," 69-70, including images on 68-69.
} 


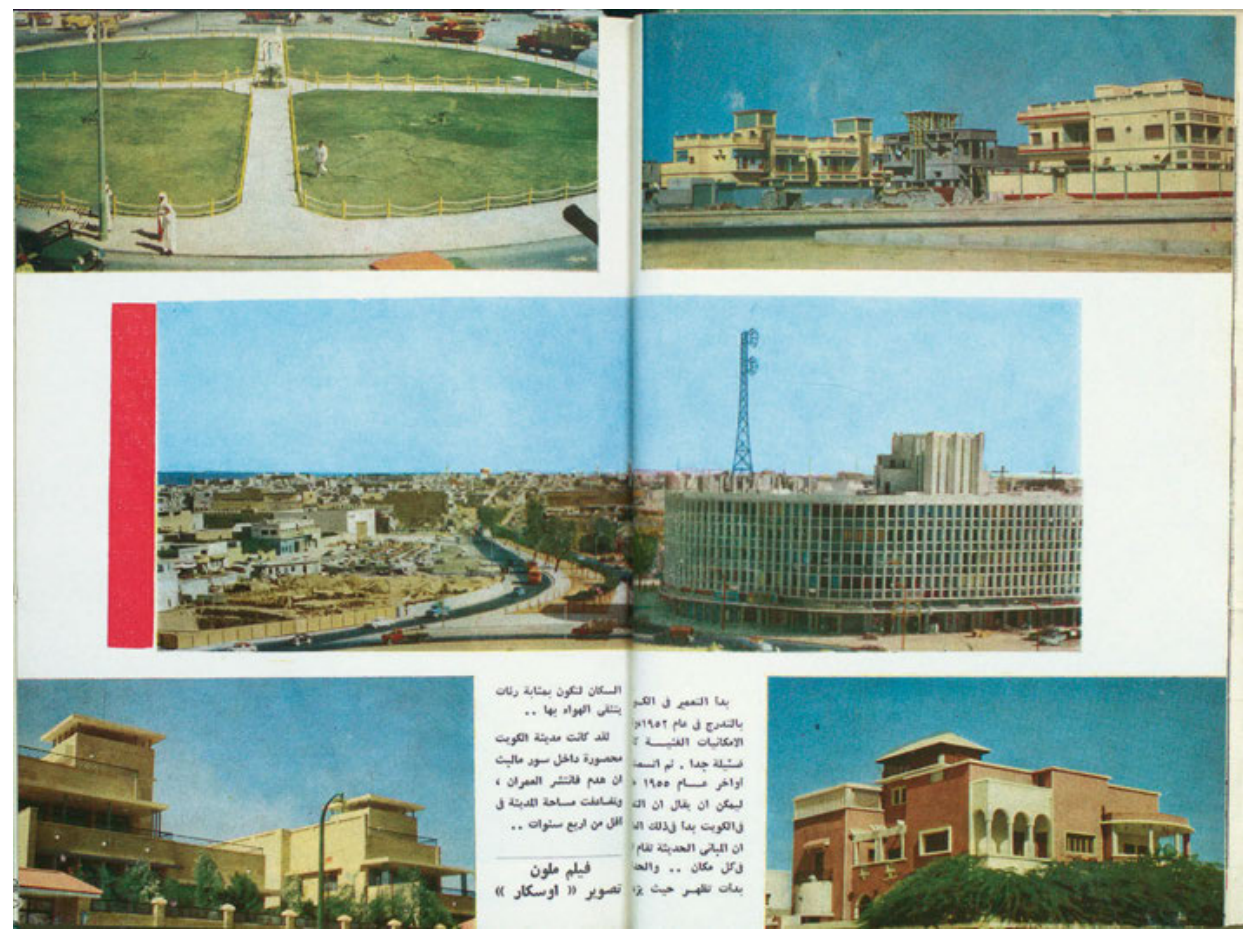

4.14 Spread from al-'Arabī, December 1959, showing new construction projects and green spaces in Kuwait City.

Have you seen Kuwait at night ...?

The most beautiful view of the city is the one you witness out of the window of your airplane while landing at night-time at Kuwait airport.

Beneath you, you will see a glittering block of lights. In the darkness of the night it reflects on the beautiful calm water of the Gulf that embraces this modern, developed city, which moves her inhabitants in thousands of cars on wide well-lit streets, not to mention that cutting-edge lighting system which uses mercury, sodium and fluorescent vapor lamps to reflect white and yellow in order to illuminate all the streets and roads.

While in the big city squares there grow millions of huge colored "neon" billboards that fill the city with beauty and joy; it is impossible against this background for a person to imagine that this region was a few years ago arid desert; the fast development has turned it upside down. ${ }^{5}$

The by-then abundant electrification of the city changed its image lastingly. In Kuwait, natural gas was the main source to generate electricity (and desalinate water) and the almost exclusive reliance on fossil energy characterizes Kuwait's energy landscape to this

59 “Al-Kuwayt fī l-layl [Kuwait at Night]," al-Arabī, no. 25 (December 1960): 140 (author's translation). 
day. ${ }^{60}$ In regard to the color photography created of Kuwait, both the examples of KOC photographs and of al-Arabīs images indicate that the unfolding of petro-modernity turned the city into an iridescence environment of color.

Color photography stood for change, for a modern Kuwait as it marked a departure from the historical black-and-white anthropo-orientalist glass plate shots of romanticized scenes of Bedouin life, pearl divers, and markets that characterized Kuwait's photographic representation in the first half of the twentieth century ${ }^{61}$ The new images functioned as transmitters of the iridescent effect, that demonstrated petroleum's powerful aesthetic and visual presence or resonance in images, in media, in objects, in the built environment, and in space in general. In strong contrast with the deep black and greasy crude oil-the oil companies' actual product-these images demonstrated what petroleum's chemical transformation was able to bring to life: a colorful lifestyle, an illuminated city, and a prospering society. It is not difficult to believe that such images created an affectionate relationship with petro-modernity.

For the KOC, Morath had been on several levels the perfect man to do the job. He was quite progressive in offering color photography for industrial customers this early on. Furthermore, for him color photography was not only the latest technological advance, but was crucial in constituting an atmosphere, an appeal that related to the equally transforming offices, homes, and lifestyles of the companies' clients and customers or at least stimulated such aspirations. Morath's determination to make such atmospheric immersion happen is captured in this anecdote by Riri Girardon, one of his last assistants in London before his death in 1977. She recalled how "he had to photograph an enormous working area with boilers, furnaces, stairways etc. all very dirty and not photogenic at all [for an industrial commission]. He simply said: 'I want this blue, that yellow, the stairs green! ... When can I come back to take the picture?" ${ }^{2}$ It is unlikely that Morath resorted to such drastic means for his Kuwait commissions. Still, the anecdote shows the importance of color for corporative photography in the eyes of this photographer. And it relates to the conscious selection of motifs and frames that Morath made of the urban space of Kuwait.

\section{The Hidden Views}

How did Morath's color photography operate to convey Kuwait City as the picture-perfect materialized promise of petro-modernity? Besides contrasting architectural forms against their flat surroundings and dipping the scene in rich colors (which were technically enhanced during the development process), constructing deliberate absences was a vital

\footnotetext{
${ }^{60}$ Hannah Ritchie, "Kuwait: Energy Country Profile," Our World in Data, accessed January30, 2021, https:// ourworldindata.org/energy/country/kuwait? country $=\sim$ KWT\#citation.

${ }^{61}$ See for example Facey and Grant, Kuwait by the First Photographers.

62 Email to the author, July 24, 2020.
} 
aspect of the image-making process. The fact that the destruction and rebuilding of preoil Kuwait is missing from Morath's supervised representations is striking, especially as the transformation was ongoing and unmissable at the time of his visits. Therefore, the photographer's role was crucial to the process of carefully navigating what to show and what to hide from view, what to highlight in color and what to disguise. Such selective depiction allowed for the ongoing messy and dusty "rebuilding" of the town to be translated into sleek, controlled, tidied, and beautiful urban vistas.

The urban and architectural overhaul of the capital could not have been overlooked by anyone who visited Kuwait in the 1950s. An employee from the BP office in London, Mr. Pattinson, who stopped by a few months prior to Morath in 1956, complained in internal communication in much detail that Kuwait was a large construction side:

\begin{abstract}
While there is a fair amount of new building going on in the Town itself, particularly building of residences and of new roads, there is still a vast amount to be done and little attempt, if any, seems to have been made to clean up and modernize the actual small streets and decrepit houses, of which the Town has always largely consisted. One can see from the two or three main boulevards which have been driven through the Town the same welter of miserable hovels and water flooded streets (it rained heavily yesterday) as always and one wonders whether there is not more window dressing going on than real improvement. ${ }^{63}$
\end{abstract}

This view of Kuwait City as heterogeneous, untidy, and only partly modernized was an impression one would have never received from seeing only Morath's images. His photographs showed almost exclusively the already modernized side of Kuwait City that fit with the oil company's public agenda of linking its own operations with fortune and progress of modern Kuwait (City); everything else was cast outside of the frame. In contrast, photographs of construction sites and scaffolded buildings in the making were frequently and matter-of-factly printed in al-Arabi ${ }^{64}$

The intact and vibrant vernacular townscape of Kuwait that still existed surrounding the patches of cleared and developed urban space remained largely omitted from the KOC photographic commission. Moreover, the destruction of the town's pre-oil architecture was rather deliberately hidden from view when compared with color photography that was taken around that time by other photographers working independently.

The recently published photographic work of Tareq Sayid Rajab (1937-2017) encompasses tranquil scenes of work in the local shipyard, observations of everyday street life, and of the archaeological excavations at Failaka Island, but especially photographs over photographs of individual buildings in the historic neighborhoods of Kuwait City

\footnotetext{
${ }^{63}$ J. M. Pattinson's Visit to Kuwait, Abu Dhabi, Persia and Iraq, January 14 to February 6, 1956, Diary No. 1, 49842, BP Archive, University of Warwick, 7-8.

${ }^{64}$ See, for instance, "Mawlid shāri` fī l-Kuwayt [Birth of a Street in Kuwait]," al-Arabī, no. 21 (August 1960): $79-84$.
} 
intra muros. ${ }^{65}$ Taken between the 1960s and the early 2000s, the photographs included in the three comprehensive and self-published photobooks substantiate a poetic and passionate long-term study of Kuwait, where time has become a salient ingredient, not only tangible in the atmospheric tranquility that Rajab captured, but also in his own longspanning perseverance and dedication to revisiting places time after time. ${ }^{66}$ Rajab never pursued a professional photographic or artistic career, working in education instead, but his lifelong productivity and the quality of his photographs, drawings, and painting speak to his artistry. In the photobooks, several scenes of urban destruction during the early 1960 s are captured that are illuminating in the context discussed here, one of which is the demolition and rebuilding of New Street (al-Shäri' al-Jadìd, today Abdullah al-Salem Street).

In 1947, the baladiyya created New Street, a new thoroughfare linking Safat Square to Sief Street and thus with the waterfront. New Street was one of the first electrified, paved, straight, and wide streets in Kuwait, for which Asseel Al-Ragam describes it as "one of the first novel explorations of urban form" by the municipality prior to the 1952 Master Plan. ${ }^{67}$ Ironically, New Street also-not old and decaying at all-fell prey to the redevelopment of the main square and its surrounding neighborhoods as part of the plan's implementation. A photograph taken by Rajab shot in 1962 presents the remaining walls of some of the buildings that had aligned New Street (fig. 4.15). The walls of former interior spaces painted in subtle tones of light yellow, green and white, are cracked open and also reveal their steel skeleton of reinforced concrete structures in the sharp morning light. At the center of the photo, the view opens onto a mural of a world map and the scene of a man and a woman, probably illustrations to entertain children. Besides, three dark clothed human figures stumble through the debris, obviously looking for treasures amid the rubble. The photograph discloses that the houses under demolition are lived spaces, for which their vanishing also erases the social memories of living in Kuwait. Moreover,

\footnotetext{
${ }^{65}$ Born in 1937 in Kuwait, Rajab received one of the first government scholarships to study art (education) in England in 1953. Upon his return to Kuwait five years later, he was already married to Jehan Wellborne (1934-2015) and father of two. In Kuwait, he first worked as a teacher, then became supervisor of the archaeological excavations at Failaka, later director of Antiquities and Museums, then manager of the KOC Display Center, and finally founder and manager of the New English School together with Jehan in 1969. In addition, the couple opened the Tareq Rajab Museum in 1980 to present their ethnographic and Islamic art collection to the public, followed by a second museum specialized in calligraphy that was opened in 2007. Besides the self-published books, Rajab's private photographic archives now await being turned into a publicly accessible collection and will hopefully receive substantial research to integrate his oeuvre into a larger visual history of the region.

${ }^{66}$ Tareq Sayid Rajab, Glimpses from the Recent Past, Kuwait 1960-65 (Kuwait: Tareq Rajab Museum, 1999); Tareq Sayid Rajab, Glimpses from the Recent Past: Kuwait 1960-1980 (Kuwait: Tareq Rajab Museum, 2005); Tareq Sayid Rajab, Glimpses from Kuwait 60-06 (Kuwait: Tareq Rajab Museum, 2007).

${ }^{67}$ Al-Ragam, "Towards a Critique of an Architectural Nahdha," 41. The road gathered many important shops and agencies on both sides that demonstratively advertised their goods under the street's columnated arcades, which also got it the name "Pillar Street."
} 


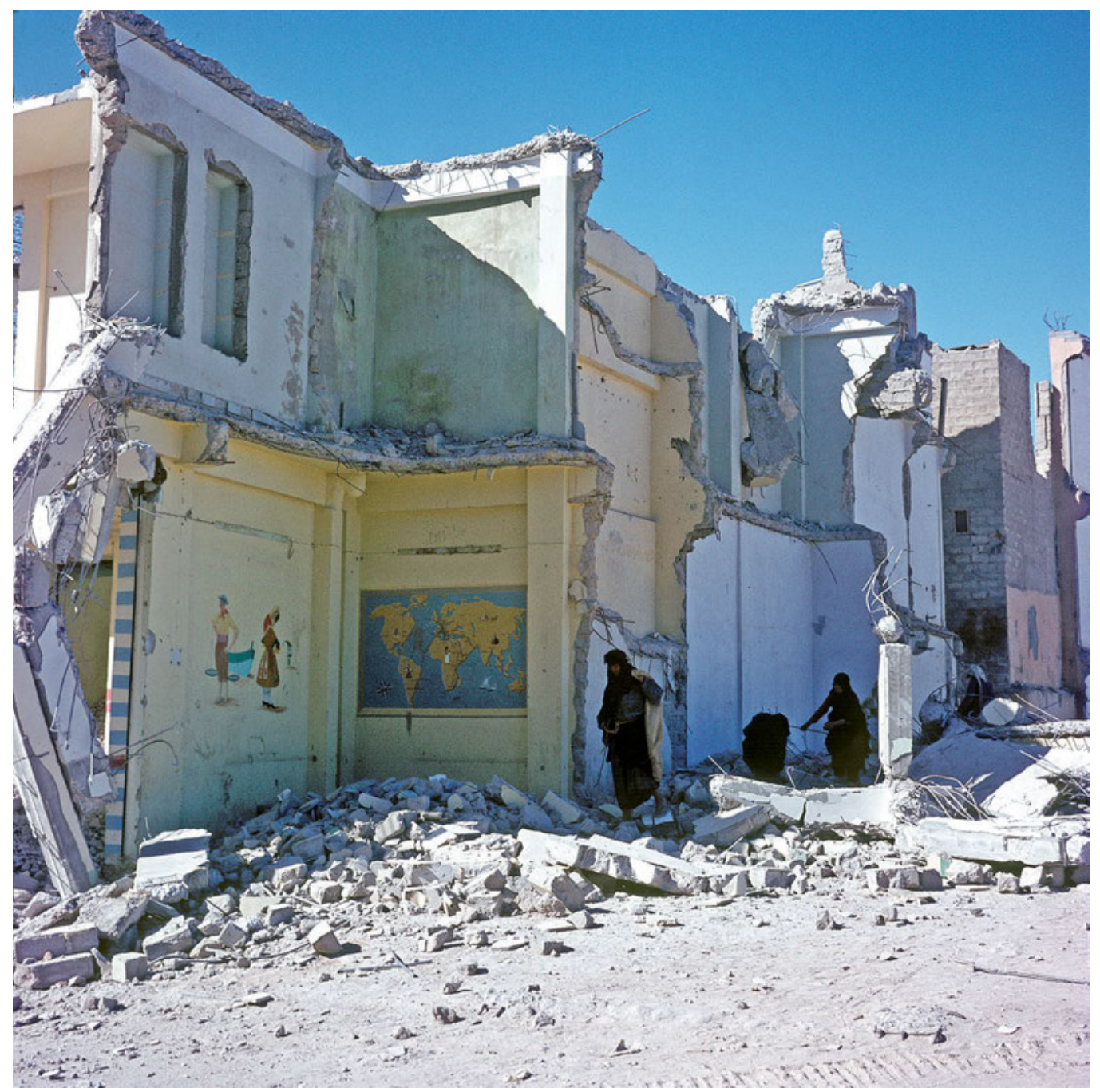

4.15 Tareq S. Rajab, Demolition of New Street, 1962. Color photograph.

it demonstrates that not only pre-oil traditional architecture was discarded, but modern architecture was too if it did not fit the overall urban concept.

Tareq Rajab's photographs allow not only to critically revisit Adolf Morath's photographic practice for the KOC, but it also offers a completely new view onto Kuwait's urban fabric during the early 1960s and therefore onto the early results of the petro-fueled urban transformation. The absence of such motifs in Morath's color photographs reveal deliberate decisions of what to select and what (not) to show. Moreover, Rajab's photos 


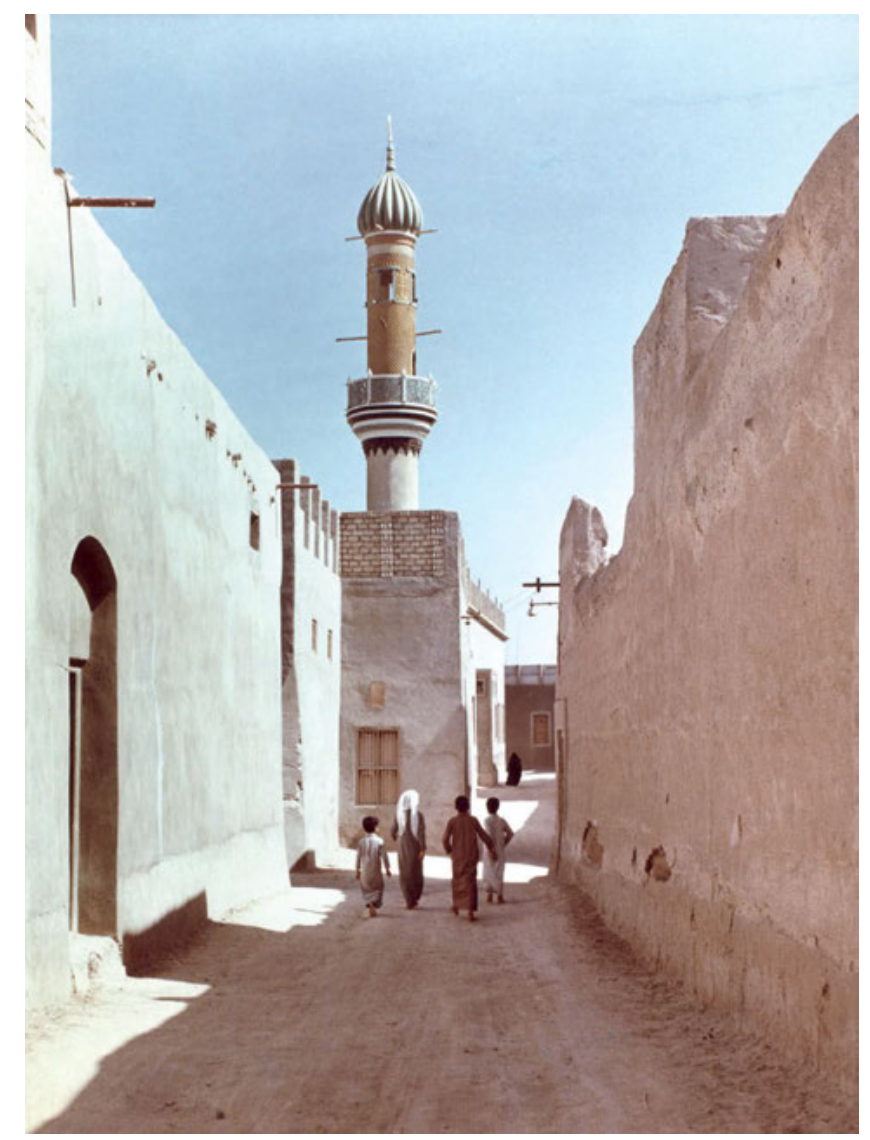

4.16 Adolf Morath, Street Scene in Kuwait Town, Showing the Minaret of a Mosque, April 1956. Color photograph.

evidence that the new commercial and administrative center of Kuwait City intra muros was not built "on sand" but on debris of the former town of Kuwait. ${ }^{68}$

The vernacular urban fabric of Kuwait's intra muros only featured in Morath's albums when it fit established notions of the decontextualized orientalist pre-oil picturesque. Typical motifs of the Kuwaiti picturesque that formed in early twentieth-century blackand-white photography included, for instance, the souk, the Bedouin market at Safat Square, mosques, or winding mud-plastered alleyways. Architectural motifs of this kind also featured in Morath's photography when it corresponded with Western expectations of an Arab Islamic city (such as mosques) or when he depicted structures that the urban planning had been singled out as worth preserving as part of the new Kuwait City (fig. 4.16).

${ }^{68}$ Ironically, the situation might not have differed so much from European postwar "rebuilding," which might explain why the British town planners kept referring to Kuwait's urban transformation as such. 


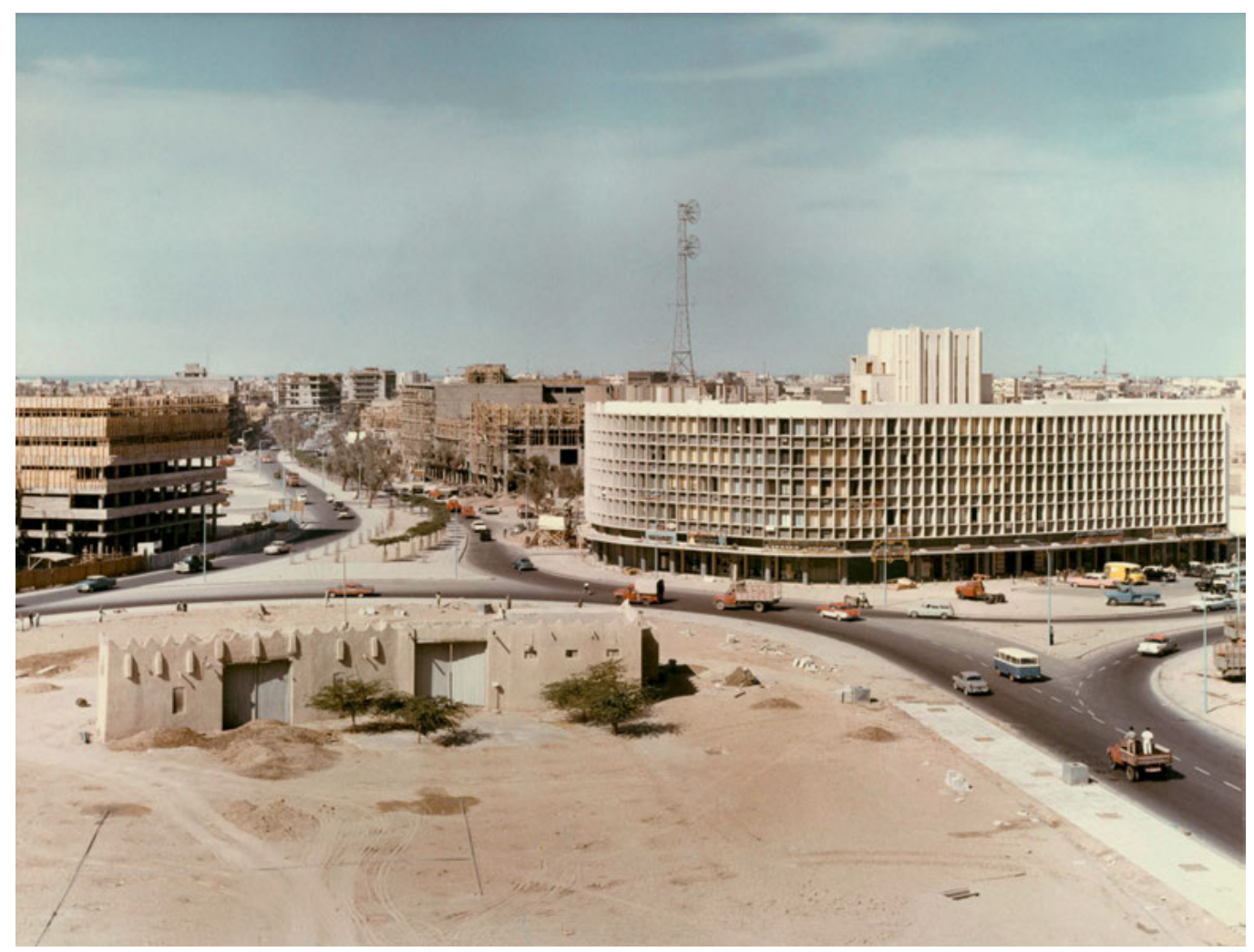

4.17 Adolf Morath, A New Office Building in Kuwait Town, April 1960. Color photograph.

The piecemeal preservation of built elements of the pre-oil urban settlement was integral to the first master plan's vision of new Kuwait and can be seen as an early attempt to create cultural heritage by decontextualizing preservation. In addition to some mosques and the royal palaces, the four town wall gates had been selected worthy of preservation. The gates were therefore not destroyed, but partly renovated and displayed in a new urban setting. Formerly integrated into the wall that had been built in 1921 and demolished in 1957, the gates now remained as fragments and thus traces of the historical urban boundary. Subsequently isolated on various roundabouts amid a sea of motorized traffic, the gates were no longer structures controlling access to Kuwait-their function had changed to open-air musealized objects. A rare color photograph taken by Morath in 1960 brings forth this process of de- and recontextualization, which brutally pitted the static old (Jahra Gate) against the dynamic new (construction sites, Fahad al-Salem Street, shiny cars) (fig. 4.17). 
In relation to the built environment, photography has long had a crucial role in playing the old off against the new, as Elizabeth Anne McCauley exemplifies using the case of Paris' radical transformation during the nineteenth century:

\begin{abstract}
Haussmann's makeover, in effect decking out grandma in new, white false teeth and a blond wig, jarringly pitted old against new and changed residents' perception of both: the faded, crumbling medieval and renaissance looking city looked even shabbier, dirtier, and smaller, whereas the pristinely white cut stone and iron trusses of modern Paris sparkled aridly-characterless, bearing the stamp of their mechanical creation. ${ }^{69}$
\end{abstract}

In the Parisian context, McCauley outlines, the overhaul resulted in photographers' preference for or increased assignments on "the new," which in turn propelled the rejection of historical buildings, vistas, and materials. In the case of Kuwait, the musealized town wall gates became, literally, a popular frame of looking at the materializing future of Kuwait. For example, al-'Arabi printed a photograph showing the development of Fahad al-Salem Street as seen through the old city gate (fig. 4.18). ${ }^{70}$ Color photography fueled the pitting of old against new even more so. It drove an aesthetic wedge between the different urban layers of time and materiality, as the rather pale palette of natural materials such as sand, mud, and coral stone were not granted a strong, colorful impression within Morath's photos. The resulting selective color images of a place where everything was new, shiny, clean, dynamic, awaiting consumption, and facilitating comfort also visually disciplined the viewer in terms of how to perceive (and in turn imagine and remember) Kuwait City.

The photography of the KOC still ran under the heading of "industrial photography" and Morath was primarily an industrial photographer. In the industrial context, the use of photography has been theorized as a form of disciplining, not only by means of the controlling presence of the photographer and the situation of freezing or posing for the shoot; rather, the photograph unfolds most power when projecting the image of an ideal working process that, simply by being depicted repeatedly, triggers the internalization of the model situation by the viewer and their subsequent self-disciplining for the purpose of fitting in. ${ }^{71}$ By analogy, Morath's photographs of a picture-perfect Kuwait City visually disciplined urban space through the careful selection of suitable motifs, the invisibility of the destruction of the already existing urban environment, and the implicit negation of the pre-oil town. Furthermore, by means of highly-curated color images the photographs showed their audiences how all of Kuwait City should look, and, over time, how their viewers were led to think that Kuwait City had in fact looked.

Morath's color photography almost invented this controlled, tidy, and colorful modern city. The more these images-and the corporate lens and seductive iridescent effect they

\footnotetext{
${ }^{69}$ Elizabeth Anne McCauley, Industrial Madness: Commercial Photography in Paris, 1848-1871, Yale Publications in the History of Art (New Haven: Yale University Press, 1994), 196.

70 "Mawlid shāri' fī l-Kuwayt [Birth of a Street in Kuwait]," 79.

${ }^{71}$ Reinhard Matz, Industriefotografie: Aus Firmenarchiven des Ruhrgebiets, Schriftreihe der Kulturstiftung Ruhr 2 (Essen: Kulturstiftung Ruhr, 1987), 112.
} 
4.18 Opening page of an article on the development of Fahad al-Salem Street in al-'Arabi, August 1960, with a view onto the street under construction through the old city wall gates.

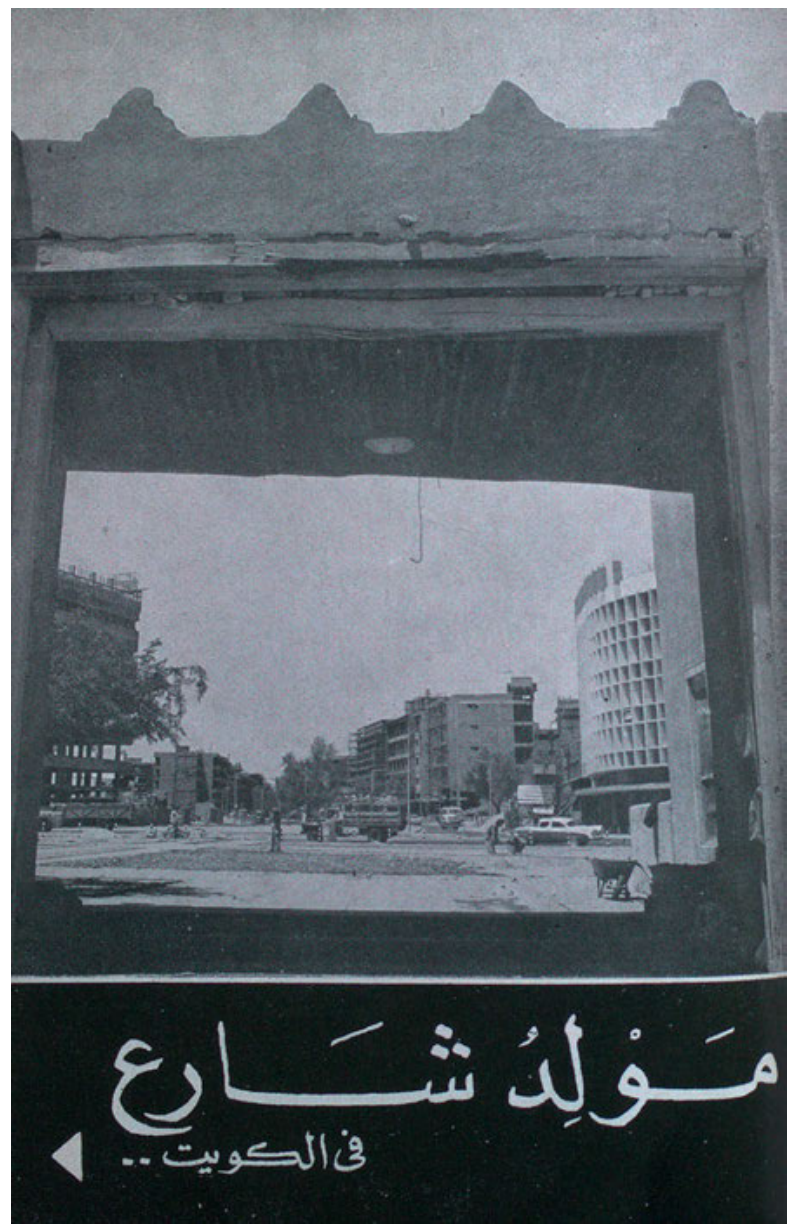

embodied-began circulating in glossy magazines, exhibition displays, and other outlets in Kuwait and beyond, the more this particular, one-sided image of 1950s Kuwait City solidified itself in popular perception as symbolic of Kuwait's mid-twentieth-century oil period. The broad dissemination and public exhibition of the oil company's photography was crucial for the proliferation of this image of Kuwait and pursued it in various ways. 


\subsection{Exhibiting Kuwait Beyond the Oil Company's Sphere}

The KOC recognized the powerful role of photography "to maintain and develop relations with the Kuwaitis" and with the home audiences of KOC shareholders for which new modes of how to distribute the pictures were necessary. ${ }^{72}$ One approach was to create public displays and soon Morath's color prints, as captured in a shot by the photographer himself, were hung as part of a permanent exhibition at the KOC Display Center in Ahmadi (fig. 4.19). Moreover, the KOC's interest resonated with the government of Kuwait's wish that the company would like to do more to publicize its activities.

In several meetings with KOC officials in summer 1957, Abdulla Mulla Saleh, the Kuwaiti ruler's official representative to the KOC, discussed the possibility of more prominent and public presentations of the photographs outside the company's sphere of direct influence, such as large-scale displays at the refreshments room of Kuwait Airport. Saleh also suggested a KOC calendar in Arabic, the sale of colored postcards based on Morath's photographs, and offering Morath photographs to "Trade Agents and Airline Agents for display here and in Beirut." ${ }^{73}$ Morath's color photographs were also included in the oil section presented in Kuwait's National Museum. ${ }^{74}$ At the time, the government obviously agreed with the visual representation of Kuwait City in Morath's photography. It can only be speculated what the motivation was, but the government obviously considered the pictures to be good publicity not just for the firm but for Kuwait in general—or at least the most professional and up-to-date photos currently available in such quantity and in color.

Following Morath's second assignment in March 1958, the KOC supplied the Department of Education with the new color photos, and "pictures, models and [a] supply of publications" also went to the Social Affairs Department. ${ }^{75}$ The 1958 photo albums show even more brand-new architectural structures rising in and around Kuwait City: cinemas, new villas, schools, medical facilities, and so on, besides, of course, the company's general operations in Ahmadi, and, the inauguration of the Refinery Extension. ${ }^{76}$ Using Morath's photographs, with their inherent corporate perspective on Kuwait's transformation, the government assisted in establishing the KOC's image of Kuwait City as the representative image of 1950s Kuwait in non-corporate and even educational contexts as well.

In Kuwait, as in other Gulf countries, photography had not yet taken root as much as in Iran or in capitals like Istanbul and Cairo. For much of the 1950s and early 1960s, the oil company's output of professional (color) photography remained unrivaled by local studies,

\footnotetext{
${ }^{72}$ Meeting on PR matters with owners' representatives, July 10, July 29, and September 20, 1957, minutes, Town Office, 1957, 106846, BP Archive, University of Warwick.

${ }^{73}$ Meeting with Mr. Mulla, October 14, 1957, minutes, ibid.

${ }^{74}$ Meeting on PR matters with owners' representatives, July 10, July 29, and September 20, 1957, minutes, ibid.

75 Town Office monthly report, March 1958, Town Office, 1957-1958.

${ }^{76}$ Kuwait Oil Company, Town Office monthly report, March 1958, ibid.; De Candole to General Manager, April 27, 1957, memorandum, Press and Publications 1957: Broadcasting.
} 


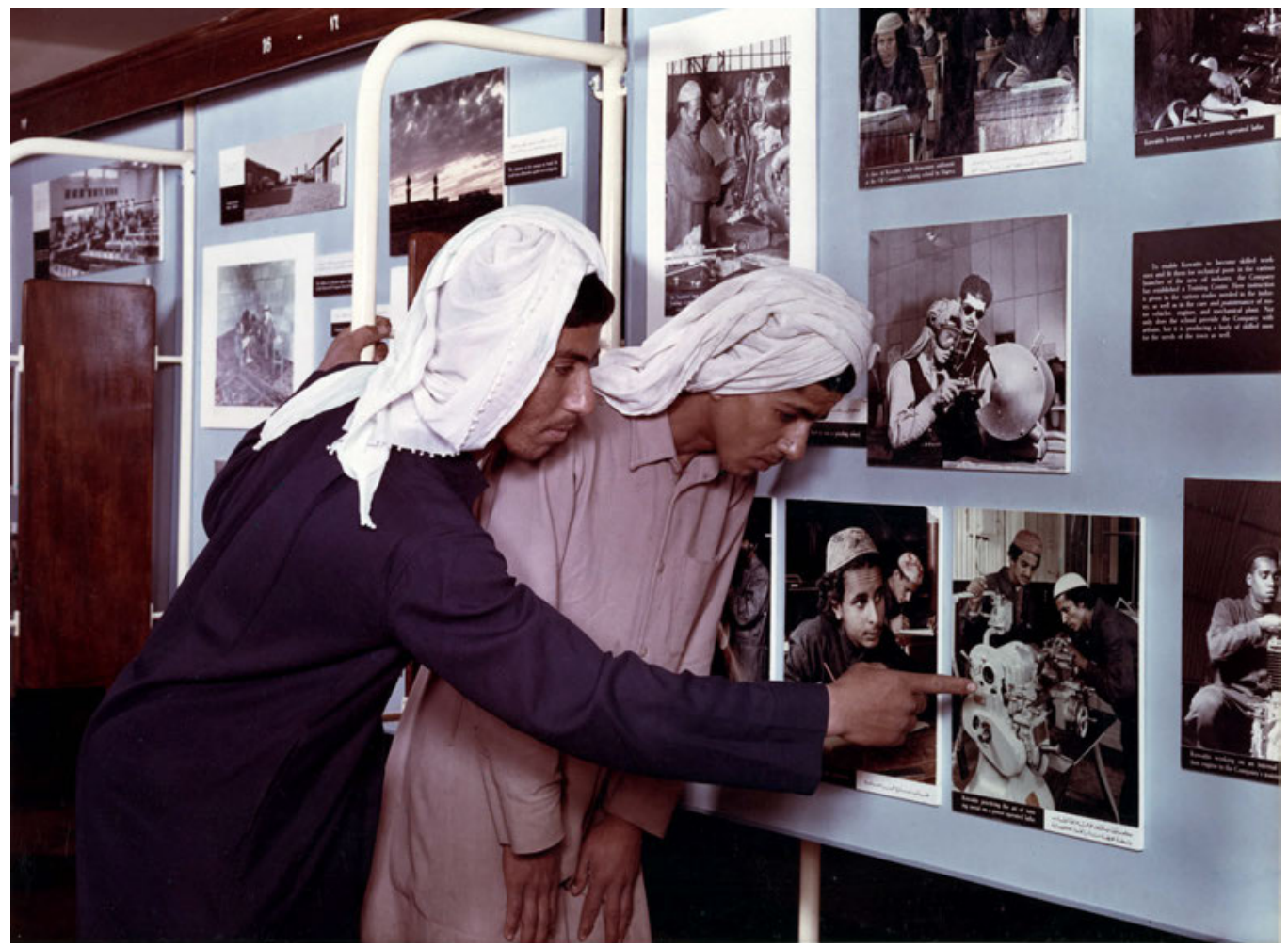

4.19 Adolf Morath, Display Centre Interior, Photographic Display, March 1958. Color photograph.

the government, or illustrated magazines like al-Arabī. This gave the company a leading edge as the source of photographic images. In contrast with SONJ, which competed with a myriad of other photography producers across the US and elsewhere, the KOC held a monopoly and its photographic collection covered seemingly all of the new Kuwait. Provided through the Town Office, the KOC's photographs were used by the government of Kuwait, international newspapers and magazines, as well as by independent writers.

In the 1950s, and in the following decades, many authors writing on the Arabian Peninsula cited the KOC, ARAMCO, and other oil companies as the source of their photographic illustrations, even in cases where neither the book nor the images dealt with the oil industry per se. For example, American writer Mary Louise Clifford credits eleven companies and organizations for the photographic illustrations used in her book The Land and People of the Arabian Peninsula (1977), six of which-including the KOC-are oil companies. ${ }^{77}$ Yet only a minority of the book's illustrations depict obvious oil company-

${ }^{77}$ Mary Louise Clifford, The Land and People of the Arabian Peninsula (Philadelphia: J. B. Lippincott, 1977). Other examples are: George Kheirallah, Arabia Reborn (Albuquerque: University of New Mexico 
related scenes. Instead, they show landscapes, people, and urban environments. The book is evidence that the oil companies' photography was acknowledged and utilized as a source of visual information not only on the Arabian oil industry but also on the Arabian Peninsula in general.

That much of Kuwait's 1950s color photography is in fact corporate photography with a specific political and economic agenda continues to be easily overlooked, especially because the motifs (like Kuwait City's urban space) offer no immediate clue as to their connection to the KOC and the photography was not watermarked or branded with a logo. Once the color photographs proliferated outside the corporate sphere of the Display Center and the KOC publications, and even outside Kuwait, contextualizing the production of these images became increasingly difficult. While SONJ had made the use of its photographs contingent on presenting each photo with the SONJ credit line, the KOC color photographs circulated independently of clues as to the context of their commission. Frequently displayed in (solo) shows of Adolf Morath's photography, for instance, the images became neutralized as independent photographic works and recast as authentic representations of Kuwait. This perspective in turn fostered the visual representation of Kuwait in line with the company's agenda and cemented the iridescent aesthetic of Kuwait's petro-modernity in broad popular perception. Again, color was key to the photographs speaking for petroleum and conveying that colorful iridescence that has made petro-modernity so attractive.

\section{Viewing Kuwait Abroad}

The 1957 exhibition Industry through My Colour Camera, held at the Ceylon Tea Centre, 22 Lower Regent Street, London, was Morath's largest solo show up to that point and took place between his first and second visit to Kuwait. ${ }^{78}$ The venue of the exhibition was special: the Ceylon Tea Centre was an initiative of several Commonwealth tea-exporting countries at a prime location in London's commercial district around Lower Regent Street, but was not only a promotional showroom for tea-related interests. Instead, it seems to have been a vibrant exhibition space for all kinds of art and design shows as well as cultural expositions. Having worked extensively for the Ceylon Tea Propaganda Board, Morath had connections to the tea industry and these links presumably helped him realize the exhibition; to what extent the KOC was involved remains unclear. ${ }^{79}$ Industry through $M y$

Press, 1952), Photographs courtesy of ARAMCO; Sanger, The Arabian Peninsula, Photographs courtesy of ARAMCO, California Texas Oil and Gulf Oil.

${ }^{78}$ L. E. Hallett, "Other London Exhibitions: Henri Cartier Bresson, Adolf Morath (Member)," The Photographic Journal 97, no. 4 (1957): 65; "Humanism in Industrial Photography: Colour, and the 'Dynamic Moment," Manchester Guardian, January 28, 1957, n.p., reprint; “Industry in Colour: An Exhibition by Adolf Morath," British Journal of Photography, February 15, 1957, n.p., reprint.

${ }^{79}$ D. M. Forrest, A Hundred Years of Ceylon Tea, 1867-1967 (London: Chatto \& Windus, 1967), photographs by Adolf Morath. This publication was edited by the Ceylon Tea Propaganda Board. Other Ceylon Tea 
Colour Camera was much discussed by British newspapers and received positive reviews. It was reported that the exhibition put on show "giant colour prints" with scenes of "the British steel industry, the oil industry in Kuwait, copper mining in Northern Rhodesia, and atomic power engineering." ${ }^{00}$ Entirely in color, all photos were developed using "the Agfa negative-positive process and made in Mr. Morath's London laboratories." ${ }^{81}$ The images were perceived as portraying "the nations' industrial power" and as marking "a new development in colour photography." 82

From here, Morath tried to expand the perception of his work not only as industrial commissions but as industrial photography as art. Correspondence with the Museum of Modern Art (MoMA) in New York from January 1958 reveals that Morath offered his "giant size colour photographs" for exhibition. ${ }^{83}$ While a MoMA exhibit did not materialize, exhibitions with a similar focus as the London show did take place, for example in Glasgow in February 1959. ${ }^{84}$ Eventually, the George Eastman House in Rochester, New York, a renowned photography museum and research institution, set up an exhibition of Morath's work from October to December 1959. Here he was introduced to the American public as "a leading British industrial photographer." ${ }^{5}$

Attesting to the successful reception of his Kuwait photographs, Adolf Morath developed the thematic exhibition Kuwait and Its People shortly thereafter, which was based on the color photographs taken on the now three trips to Kuwait on behalf of the Kuwait Oil Company and the government of Kuwait, who eventually commissioned him directly, too. In November 1960, the show premiered also at the Ceylon Tea Centre, and the following May it was shown at the Near East Foundation in New York. The Foundation's invitation reads as follows:

Centers existed in Copenhagen and Melbourne. Moreover, later that year, KOC officials decided that "a new display of Morath photos will be prepared for exhibition at schools and other centres in the UK"; but it is not verifiable whether and to what extent the oil company supported, financed, or organized this or other of Morath's exhibitions outside of Kuwait. Meeting on PR matters with owners' representatives, July 10, July 29, September 20, 1957, Town Office, 1957.

${ }_{80}$ “Camera Captures Industrial Drama: Colour Prints on Show," Manchester Guardian, May 28, 1957, n.p., reprint.

${ }^{81}$ Hallett, "Other London Exhibitions," 65.

82 "Pictures of Power," The Birmingham Post \& Gazette, January 29, 1957, 4; "Scenes from Oil Industry in London Exhibition," The Birmingham Post \& Gazette, January 28, 1957, 7.

${ }_{83}$ Adolf Morath and MoMA, January 7, January 8, January 22, 1958, letters, Adolf Morath Photography Bio File, Museum of Modern Art Archives.

${ }^{84}$ The exhibition was held at the McLellan Galleries, Glasgow, February 3-11, 1959; see M. MacDonald, "Exhibition of Industrial Photographs: Brilliance of Works," The Glasgow Herald, February 4, 1959, n.p., reprint; "The Snapshot Schoolboy Is Now a Top Photographer," n.p.

${ }^{85}$ The exhibition at George Eastman House was held from October 21 to December 15, 1959; see "Noted British Industrial Photographer, Adolf Morath, Exhibits at George Eastman House," news release, October 21, 1959, George Eastman House Archives, Rochester, New York. 
The Exhibition will show by means of large colour photographs the whole fascinating story of Kuwait. It will stress not the old Kuwait of herdsmen that has so often been depicted, but the Kuwait which has taken shape in the last few years, hand in hand with the development of the country's oil resources: the modern houses, the mosques, the schools and hospitals, the new harbour, the people at work and at play, the oil installations, the town of Kuwait at night and from the air. ${ }^{86}$

That the text echoes the KOC's The Story of Kuwait is surely no accident. Regardless of whether the KOC supported this exhibition or not, its narrative strongly reverberated in the text, which interlinked the "development" of the oil industry with Kuwait's urban transformation. Colorful images of the rapidly growing city were key evidence to substantiate this relationship.

Through exhibitions like these, Morath's color photographs of Kuwait reached a much wider audience than that initially targeted and accessible by the oil company. Most importantly though, through the images' transfer into the sphere of art and culture in form of museum exhibitions outside of Kuwait and beyond company properties, the corporate origin (and agenda) of the photographs was diffused, even neutralized, and eventually recast as authentic artistic expressions of a British photographer who had visited Kuwait.

\subsection{Color Photography Showcases Petro-Modernity as Iridescence}

The (color) photography of the Kuwait Oil Company has lastingly influenced the way in which Kuwait's recent past is remembered today. It was through the exciting and still expensive medium of color photography that the electric lights of mid-twentiethcentury consumerism and modernization were suddenly switched on, bringing the urban transformation of Kuwait, vibrant and pretty, to light and life for (inter)national audiences. These pictures, among other images, still circulate in current debates on the modern era or oil period of Kuwait on social media platforms and private collections. In these contexts, they are often taken as authentic visual evidence of that period, usually without knowledge of their commission and their initial agenda. The color photography shot by Adolf Morath for the KOC is a testament to the strong impact of oil companies on the region's urban visual culture.

In the Arabian Peninsula, where the institutionalization of archival facilities and the continuous maintenance of collecting and preserving (visual) material remain challenging to this day, oil companies have emerged as important producers and distributors of professional photography. Often their collections reach back more than fifty years and cover a wide scope of motifs and sites far beyond the oil compound in excellent quality. These photographic archives speak to the current renewed and often nostalgic interest in

\footnotetext{
${ }^{86}$ Invitation to the exhibition Kuwait and its People at the Near East Foundation, New York, May 25, 1961, Adolf Morath Photography Bio File, Museum of Modern Art Archives (author's emphasis).
} 
the (early) oil period of the region and will most likely continue to gain in importance as both cherished and contested repositories of social memory.

However, the more these images circulate as digital images, as mobile phone photos taken of Xerox scans of copies of the original photographic prints, the more difficult it becomes to historically contextualize them. The KOC photographs originated from a corporate environment with a concerted political, economic, and aesthetic agenda. They are not simply photographic representations of Kuwait in the late 1950s and early 1960s, they embody the picture of Kuwait that the oil company wanted to convey for its own multifold purposes. It is therefore important to carefully re-situate the photos in the oil archive and to disclose their provenance so as not to render oneself overpowered by the iridescent persuasiveness of the colorful images that hide just as much as they convey about what life was like in Kuwait.

In the case of Kuwait, the oil company created a highly polished, clean, and controlled image of Kuwait City. The appeal of these photographs, especially at the time when they were first published, is of course due to Adolf Morath's careful curation of the motifs, which showed the modern parts of Kuwait and not the remains of the pre-oil town or its destruction. However, color photography became crucial to creating a dynamic atmosphere and to conveying the proliferation of color according to the contemporary experience of the city evolving in the context of petro-modernity. Photographic representations of Kuwait City served to turn the city into a highly visible showcase of the seemingly unlimited dimensions of growth achievable when partaking in petromodernity, metaphorized as a colorful concrete city springing from the desert. Color photographs in particular enabled, quite literally, the display in urban space of the new materials, colors, and textures provided for by petroleum.

By including images of Kuwait City's urban transformation in KOC publications such as The Story of Kuwait and thus into its corporate cosmos, the company instrumentalized the photographs to position itself as a patron of modern Kuwait, as its de facto motor of transformation-and petroleum as the fuel (and money) to do so. This way the KOC intended professional photography to challenge such allegations that the extractive nature of oil industries in general and of foreign-run companies such as the KOC in particular pursued the withdrawal of petroleum (and of capital) at any cost while readily accepting the drain and destruction of landscapes, societies, and local economies. The KOC's color photography are one example of the important role of urban images of the mid-twentiethcentury Gulf cities as iridescent promotors of petro-modernity and petro-capitalism with a lasting effect on the future reputation of these cities.

The new photography of modern Kuwait not only benefitted the oil company's public relations efforts, but also delivered evidence to challenge notions of timelessness and standstill connected with Kuwait. It allowed them to push a new image, a new narrative of Kuwait as dynamic, progressive, and modern that also appealed to the government of Kuwait and other audiences outside of Kuwait. The appeal of this narrative most likely also accounts for the ongoing affection for these photos. 
From the mid-1950s onward, the government of Kuwait started challenging the KOC's pole position in the field of image production about and branding of Kuwait in a way that both affirmed and deviated from the promotional strategy, metaphors, and style the company had initiated. Media such as the new government gazette and the first set of Kuwaiti postage stamps strove to manifest a new visual presence and rhetoric of the state in which the visual representation of the capital city played an equally important role. 